\title{
Measuring currents, ice drift, and waves from space: the Sea surface KInematics Multiscale monitoring (SKIM) concept
}

\author{
Fabrice Ardhuin ${ }^{1}$, Yevgueny Aksenov ${ }^{2}$, Alvise Benetazzo ${ }^{3}$, Laurent Bertino $^{4}$, Peter Brandt ${ }^{5}$, Eric Caubet $^{6}$, \\ Bertrand Chapron $^{1}$, Fabrice Collard ${ }^{7}$, Sophie Cravatte ${ }^{8}$, Jean-Marc Delouis ${ }^{1}$, Frederic Dias ${ }^{9}$, Gérald Dibarboure ${ }^{10}$, \\ Lucile Gaultier $^{7}$, Johnny Johannessen ${ }^{4}$, Anton Korosov ${ }^{4}$, Georgy Manucharyan ${ }^{11}$, Dimitris Menemenlis ${ }^{12}$, \\ Melisa Menendez ${ }^{13}$, Goulven Monnier ${ }^{14}$, Alexis Mouche ${ }^{1}$, Frédéric Nouguier ${ }^{1}$, George Nurser ${ }^{2}$, Pierre Rampal $^{4}$, \\ Ad Reniers $^{15}$, Ernesto Rodriguez ${ }^{12}$, Justin Stopa ${ }^{1}$, Céline Tison ${ }^{10}$, Clément Ubelmann ${ }^{15}$, Erik van Sebille ${ }^{16}$, and \\ Jiping $\mathrm{Xie}^{4}$ \\ ${ }^{1}$ Laboratoire d'Océanographie Physique et Spatiale (LOPS), Univ. Brest, CNRS, Ifremer, IRD, Brest, France \\ ${ }^{2}$ National Oceanographic Center, Southampton, SO14 3ZH, UK \\ ${ }^{3}$ Institute of Marine Sciences, National Research Council (ISMAR-CNR), Venice, Italy \\ ${ }^{4}$ Nansen Environmental and Remote Sensing Center, Bergen, Norway \\ ${ }^{5}$ GEOMAR Helmholtz Centre for Ocean Research Kiel, Kiel, Germany \\ ${ }^{6}$ Thales Alenia Space, Toulouse, France \\ ${ }^{7}$ OceanDataLab, 870 Route de Deolen, 29280 Locmaria Plouzané, France \\ ${ }^{8}$ LEGOS, Université de Toulouse, CNES, CNRS, IRD, Toulouse, France \\ ${ }^{9}$ University College, Dublin, Ireland \\ ${ }^{10} \mathrm{CNES}, 18$ avenue Edouard Belin, 31400 Toulouse, France \\ ${ }^{11}$ Division of Geological and Planetary Sciences, California Institute of Technology, Pasadena, California, USA \\ ${ }^{12}$ Earth Sciences Division, Jet Propulsion Laboratory, California Institute of Technology, Pasadena, California, USA \\ ${ }^{13}$ Environmental Hydraulics Institute "IH Cantabria” Universidad de Cantabria, Santander, Spain \\ ${ }^{14}$ Scalian Alyotech, 2 rue Antoine Becquerel, 35700 Rennes, France \\ ${ }^{15}$ Collecte Localisation Satellite (CLS), 8-10 Rue Hermes, 31520 Ramonville St-Agne, France \\ ${ }^{16}$ Institute for Marine and Atmospheric Research, Utrecht University, Utrecht, the Netherlands
}

Correspondence: Fabrice Ardhuin (ardhuin@ifremer.fr)

Received: 19 July 2017 - Discussion started: 31 July 2017

Revised: 8 March 2018 - Accepted: 15 March 2018 - Published: 15 May 2018

\begin{abstract}
We propose a satellite mission that uses a nearnadir Ka-band Doppler radar to measure surface currents, ice drift and ocean waves at spatial scales of $40 \mathrm{~km}$ and more, with snapshots at least every day for latitudes 75 to $82^{\circ}$, and every few days for other latitudes. The use of incidence angles of 6 and $12^{\circ}$ allows for measurement of the directional wave spectrum, which yields accurate corrections of the wave-induced bias in the current measurements. The instrument's design, an algorithm for current vector retrieval and the expected mission performance are presented here. The instrument proposed can reveal features of tropical ocean and marginal ice zone (MIZ) dynamics that are inaccessible to other measurement systems, and providing global monitor-
\end{abstract}

ing of the ocean mesoscale that surpasses the capability of today's nadir altimeters. Measuring ocean wave properties has many applications, including examining wave-current interactions, air-sea fluxes, the transport and convergence of marine plastic debris and assessment of marine and coastal hazards.

\section{Introduction}

Because the ocean surface is the interface between ocean, atmosphere and land, surface currents play an important role in defining the fluxes of heat, momentum, carbon, water, etc. 
among Earth system components. The ocean surface velocity combines surface currents (mainly driven by winds, density gradients, and tides), with a wave-induced drift, known as Stokes drift. This total mass movement transports surface heat, salt and everything that is in the upper ocean, natural or man-made, including marine plastic debris (van Sebille et al., 2015). While vastly improving over the satellite era, there are still important gaps in our knowledge of ocean currents and waves. Satellite altimeters have been around for over 25 years, revealing mesoscale ocean dynamics and providing a global view of the wind-generated waves.

Still, the along-track sea level anomaly misses most of the multi-scale motion of the ocean surface, because of limited resolution (e.g., Fu and Ubelmann, 2014) and because a large component of surface currents is not in geostrophic balance. The second aspect is particularly relevant near the Equator (Cravatte et al., 2016), in strong western boundary currents (Rouault et al., 2010; Rio et al., 2014) and remains a problem everywhere due to near-inertial motion (Kim and Kosro, 2013; Poulain et al., 2016; Elipot et al., 2016). Altimeter and synthetic aperture radar (SAR) processing difficulties and the small scales of currents combine to make the edge of the sea ice a blind spot in today's observation systems (Korosov and Rampal, 2017).

Other available measuring systems are very local, such as high-frequency (HF) radars, or global with sparse coverage, such as drifters (e.g., Elipot et al., 2016). As shown in Fig. 1, a single polar orbiting satellite with a swath width of $270 \mathrm{~km}$ could extend the capability of existing systems for monitoring ocean surface velocities, in particular for wavelengths between 60 and $1000 \mathrm{~km}$ and periods ranging from 3 to 30 days.

Because larger scales move slower, the coarser time resolution at the Equator also yields a coarser spatial resolution.

As detailed below, the Sea surface KInematics Multiscale monitoring (SKIM) mission, would use map surface waves and currents with $6 \mathrm{~km}$ footprints resolved at $4 \mathrm{~m}$ resolution in range. These footprints are distributed across a $270 \mathrm{~km}$ wide swath, but do not cover the entire swath, leaving a gap between the features smaller than $6 \mathrm{~km}$ resolved with a footprint and the features larger than $20 \mathrm{~km}$ fully mapped across the swath. As the ocean is viewed in less than 1 min during a single pass, the observed scene is basically a snapshot in which many ocean processes are aliased. Only those current features that vary on timescales of several days, or that have a constant phase and amplitude such as tides, can be measured without ambiguity. Evidence from HF radars in coastal areas suggests that even near-inertial motion is coherent over timescales as large as 6 days at mid-latitudes (Kim and Kosro, 2013). Hence even if currents are measured only every 3 days, they can still provide useful constraints on the ocean circulation.

Measurements of ocean surface currents from remote sensing platforms have been obtained using a wide range of techniques. The most widely used at large scales includes satellite altimeters, possibly combined with scatterometer

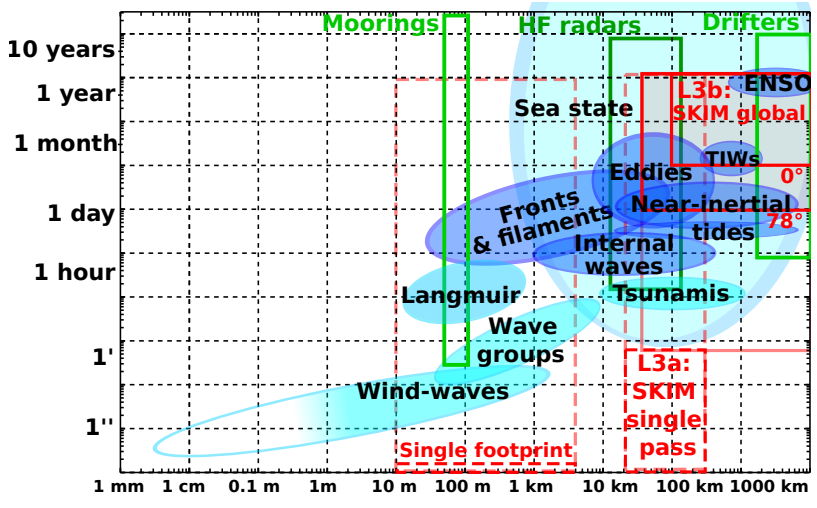

Figure 1. Typical periods and wavelengths of processes that contribute to the surface velocity. Ocean circulation processes are in dark blue, wave-related processes are in light blue. Scales resolved by existing measuring systems appear in green, and the proposed SKIM satellite mission in red, with different scales resolved in a single-pass level 3 a product (L3a), or the full time history of the measurements gridded as a level $3 b$ product (L3b). Note that limited coverage in space or time leads to aliasing of the unresolved scales that are in the pink boxes (e.g., Stammer et al., 2000; Gille and Hughes, 2001). Due to the polar orbit, the resolved periods vary from 12 days at the Equator $\left(0^{\circ}\right)$ to 1 day at $78^{\circ}$ latitude.

wind and in situ drifters (e.g., Bonjean and Lagerloef, 2002; Sudre et al., 2013; Rio et al., 2014). Other techniques such as image processing of optical or SAR imagery have been demonstrated in many regions (see Isern-Fontanet et al., 2017, for a review). Direct measurement of the ocean surface current vector using Doppler techniques is now widely used in land-based radar systems, with operational use for current mapping in the $\mathrm{HF}$ band, ranging from 3 to $30 \mathrm{MHz}$ (Barrick, 1972). Interesting results have also been reported with landbased microwave radars (Forget et al., 2006, 2016), but the measured radial velocity is not fully understood.

Air- and spaceborne measurements of surface velocity have been taken with across-track interferometric (ATI) SARs using two antennas (Goldstein and Zebker, 1987). This has been generalized to squinted ATI SARs to provide the two components of the current vector (Buck, 2005; Wollstadt et al., 2016). More recently, Chapron et al. (2005) have shown the potential of using the Doppler centroid of ocean backscatter received by a single antenna. Although this measurement is more noisy than ATI, resulting in coarser effective resolution, the velocity given by the Doppler centroid is equivalent to an ATI measurement (Romeiser et al., 2014). Hence, the Doppler centroid method is a cost-effective solution for deriving current information from existing satellite missions such as Envisat and the Sentinel 1 constellation. This has already led to scientific application on the monitoring of intense currents (Rouault et al., 2010).

This demonstration of Doppler oceanography from space, using measurements of opportunity, has led us to propose a specially built Doppler radar altimeter that uses nadir and off- 
nadir beams in Ka-band. SKIM is designed to measure both the horizontal surface velocity vector $(\boldsymbol{U}, \boldsymbol{V})$, i.e., surface current or ice drift, and the directional wave spectrum $E(k$, $\theta$ ), where $k$ is the wavenumber and $\theta$ is the azimuth of wave propagation. Wave spectra are used to correct for a waveinduced bias in the Doppler velocity. The purpose of the present paper is to describe the measurement principle and the expected instrument performance based on a preliminary analysis.

Doppler measurements start from a line-of-sight velocity $U_{\mathrm{LOS}}$ which contains a very large non-geophysical component $U_{\mathrm{NG}}$ due to the relative motion of the spacecraft relative to the solid Earth. The anomaly relative to $U_{\mathrm{NG}}$ can be interpreted as a horizontal geophysical Doppler contribution,

$U_{\mathrm{GD}}=\left(U_{\mathrm{LOS}}-U_{\mathrm{NG}}\right) / \sin \left(\theta_{i}\right)$,

where $\theta_{i}$ is the local incidence angle. The geometry of the measurement is illustrated in Fig. 2.

Common to ATI and Doppler centroid techniques, is the contribution of orbital velocity of wind-generated waves to the geophysical velocity $U_{\mathrm{GD}}$, in the form of a wave bias $U_{\text {WB }}$ (Chapron et al., 2005; Mouche et al., 2008; Martin et al., 2016), so that the radial current (projected onto the mean sea surface in the azimuth of radar look) is

$U_{\mathrm{R}}=\left(U_{\mathrm{GD}}-U_{\mathrm{WB}}\right)$.

$U_{\mathrm{R}}$ is the radial component of the Lagrangian mean velocity vector $\boldsymbol{U}=(U, V)$, defined from the average drift velocity of water parcels. This Lagrangian mean drift is $\boldsymbol{U}=\boldsymbol{U}_{\mathrm{E}}+\boldsymbol{U}_{\mathrm{S}}$, the sum of a quasi-Eulerian current (Jenkins, 1989) $\boldsymbol{U}_{\mathrm{E}}$ and a Stokes drift $\boldsymbol{U}_{\mathrm{S}}$ (Stokes, 1849). $\boldsymbol{U}_{\mathrm{S}}$ is the surface drift vector due to waves, that arises from a correlation between the displacement and gradients of the velocity field: forward particle velocity at a crest is faster than the backward velocity at a trough. The Sto $U_{\mathrm{S}}$ at the sea surface is on the order of 1.0 to $1.8 \%$ of the wind speed, typically larger than the local windinduced quasi-Eulerian current known as the Ekman current, unless a strong stratification is present (Ardhuin et al., 2009).

Previous applications have used the radial wind speed $U_{10, \mathrm{R}}$ projected in the range direction as a proxy for estimating $U_{\mathrm{WB}}$. As we review in Sect. 2, this wind speed proxy is not sufficient for obtaining accurate instantaneous current velocities. We therefore propose in Sect. 3 an algorithm for estimating $U_{\mathrm{WB}}$ within 10 to $20 \%$, based on the measurement of waves with a rotating radar system. This technique forms the conceptual basis for SKIM. Its expected overall performance and effective resolution is described in Sect. 4. A summary and review of potential applications and improvements in processing follow in Sect. 5. The present paper focuses on currents, and a detailed description of wave measuring capabilities with SKIM will be given elsewhere.

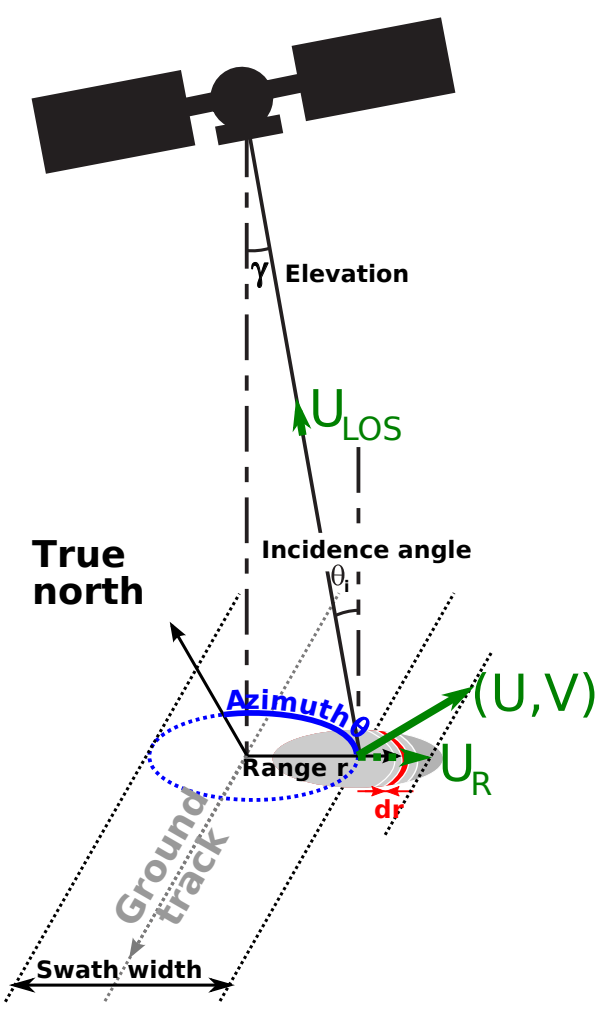

Figure 2. Geometry of measurement from a radar with a local incidence angle $\theta_{\mathrm{i}}$, looking towards azimuth $\theta$. For simplicity of the schematic, we have taken $U_{\mathrm{WB}}=0$ and $U_{\mathrm{NG}}=0$, so that the lineof-sight velocity is simply $U_{\mathrm{LOS}}=(U \sin \theta+V \cos \theta) \sin \theta_{\mathrm{i}}$. Note that the diameter of the footprint $(6 \mathrm{~km})$ is exaggerated compared to the swath width $(270 \mathrm{~km})$ for readability. The small difference between elevation $\gamma$ and incidence angle $\theta_{\mathrm{i}}$ is due to the Earth curvature.

\section{Importance of mean slope speed or Stokes drift}

\subsection{Expected and observed dependence of $U_{\mathrm{WB}}$}

Because the velocity or phase shift recorded by a radar corresponds to the velocity weighted by the backscattered power, the wave-induced bias $U_{\mathrm{WB}}$ is related to the mean slope velocity vector, $\boldsymbol{m} \boldsymbol{s} \boldsymbol{v}=\left(<\partial^{2} \zeta / \partial x \partial t>,<\partial^{2} \zeta / \partial y \partial t>\right)$, due to the correlation between the normalized radar cross section (NRCS or $\sigma_{0}$ ) and the surface slope (e.g., Nouguier et al., 2018). For linear waves, $\boldsymbol{m} \boldsymbol{s} \boldsymbol{v}$ is equal to twice the surface Stokes drift vector $\left(\boldsymbol{U}_{\mathrm{S}}, \boldsymbol{V}_{\mathrm{S}}\right)$.

In practice $U_{\mathrm{WB}}$ is very close to a gain factor $G$ multiplied by $U_{\mathrm{S}, \mathrm{R}}$, the surface Stokes drift projected on the range direction (Chapron et al., 2005) with an additional correction proportional to the Stokes drift in the azimuthal direction (Nouguier et al., 2018). $G$ is a function of radar frequency, incidence angle and sea state. Figure 3 shows the expected dependence of $G$ on the incidence angle for average wind speeds and a fully developed sea state, using a physical optics model or Kirchhoff approximation in the upwind direction 


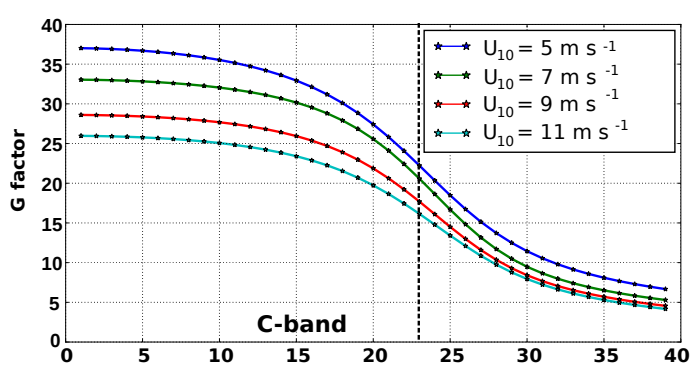

(a) Incidence (degrees)

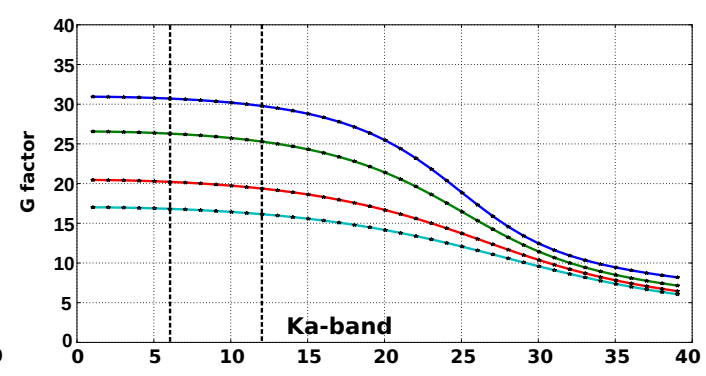

(b) Incidence (degrees)

Figure 3. $G$ factor in the upwind looking direction estimated using a Kirchhoff approximation for a wave spectrum given by Elfouhaily et al. (1997), representing a fully developed sea state for wind speeds $U_{10}$ ranging from 5 to $11 \mathrm{~m} \mathrm{~s}^{-1}$. (a) C-band, appropriate for Envisat and Sentinel 1, (b) Ka-band for SKIM. The vertical dashed lines show the incidence angles of the instruments.
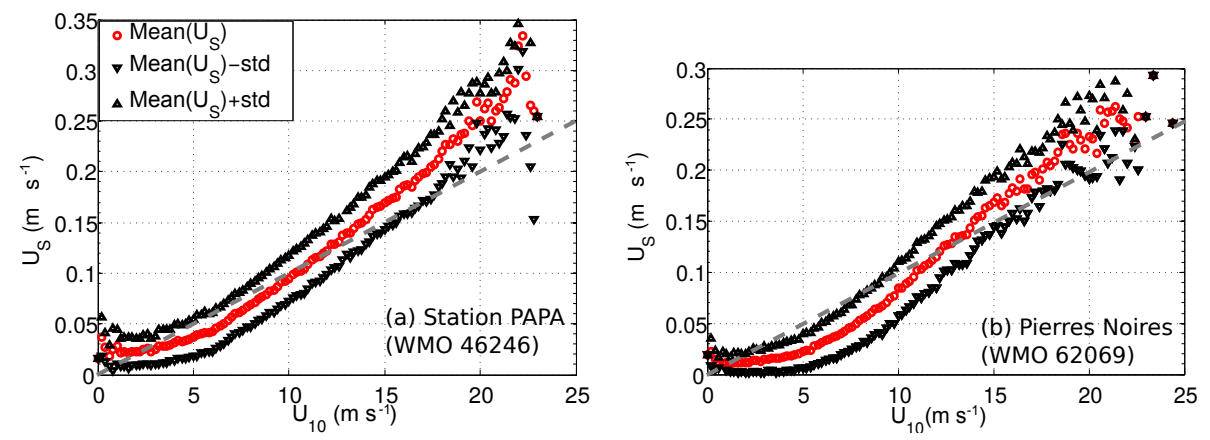

Figure 4. Example of mean value (in red) of the Stokes drift vector norm $U_{\mathrm{S}}=\left|\left(U_{\mathrm{S}}, V_{\mathrm{S}}\right)\right|$ as a function of wind speed for two locations: station PAPA in the northeast Pacific, and buoy 62069 off the French Atlantic coast. The black symbols show the mean \pm 1 standard deviation for each wind speed. The dashed grey line is $U_{\mathrm{S}}=0.01 U_{10}$. This estimation covers only frequencies up to $0.58 \mathrm{~Hz}$.

(e.g., Nouguier et al., 2018). A typical order of magnitude in Ka-band for incidence angles less than $15^{\circ}$ is $G \simeq 25$, which is similar to values in C-band at higher incidence angles.

This dependency of $U_{\mathrm{WB}}$ on the radial Stokes drift $U_{\mathrm{S}, \mathrm{R}}$ and incidence angle $\theta_{i}$, as well as the order of magnitude of $G$, are confirmed by the analysis of platform-based measurements by Yurovsky et al. (2018) and by airborne measurements from the AirSWOT instrument (e.g., Nouguier et al., 2018).

\subsection{Estimation of $U_{\mathrm{WB}}$}

The surface Stokes drift vector $\boldsymbol{U}_{\mathrm{S}}=\left(U_{\mathrm{S}}, V_{\mathrm{S}}\right)$ can be estimated from the directional wave spectrum, assuming linear wave theory (Kenyon, 1969). The wave spectrum $E(k, \theta)$ represents the distribution of the surface elevation variance across wavenumbers $k$ and azimuthal wave propagation directions $\theta$. For waves in deep water this is

$\left(U_{\mathrm{S}}, V_{\mathrm{S}}\right)=2 \sqrt{g} \int_{0}^{2 \pi} \int_{0}^{\infty}(\sin \theta, \cos \theta) k^{1.5} E(k, \theta) \mathrm{d} k \mathrm{~d} \theta$.

This integral can be estimated from the first moments $a_{1}$ and $b_{1}$ measured by directional wave buoys from the co- spectra of vertical and horizontal accelerations (e.g., Kuik et al., 1988).

The projected Stokes drift $U_{\mathrm{S}, \mathrm{R}}$ is correlated with the wind speed in the radial direction $U_{10, \mathrm{R}}$. Hence, the approximation of $U_{\mathrm{WB}}$ as a function of $U_{10, \mathrm{R}}$ is a logical first step proposed by Chapron et al. (2005) and Mouche et al. (2008), and used by Rouault et al. (2010) to retrieve surface currents.

However, for a given wind speed the sea state introduces a typical variation of $U_{\mathrm{S}, \mathrm{R}}$ that has a standard deviation of $40 \%$. Further, the distribution of $U_{\mathrm{S}, \mathrm{R}}$ as a function of $U_{10, \mathrm{R}}$ can change significantly from one region of the ocean to another. These properties are illustrated in Fig. 4 with data for the years 2011 to 2015, from the northeast Pacific station PAPA, in deep water (Thomson et al., 2013), and a northeast Atlantic coastal buoy, Pierre Noires, at $60 \mathrm{~m}$ depth (Ardhuin et al., 2009). In both cases the wind speed is taken from operational ECMWF analyses. Directional wave moments were downloaded from CDIP and CEREMA. The Stokes drift was integrated over the frequency range of the Datawell Waverider buoy, from 0.025 to $0.58 \mathrm{~Hz}$.

Using the order of magnitude $U_{\mathrm{S}} \approx 0.01 U_{10}$, the sea-state variation means that a wind-only proxy for $U_{\mathrm{WB}}$ gives a root mean square error (RMSE) on the current on the order of $40 \% \times G \times 0.01=10 \%$ of the wind vector. With a median wind speed of $7 \mathrm{~m} \mathrm{~s}^{-1}$, this is a $70 \mathrm{~cm} \mathrm{~s}^{-1}$ error in the wind 
direction for $\mathrm{C}$-band at $23^{\circ}$ of incidence, or Ka-band at $12^{\circ}$. Such a high value is not acceptable for a single satellite pass, but these errors cancel out when the Doppler velocity is averaged over many satellite passes, 10 or more, as done by Collard et al. (2008) and Rouault et al. (2010). Even at the higher incidence angles of $58^{\circ}$ proposed by Bourassa et al. (2016), for which we expect $G \simeq 7$ in Ka-band, the wave bias is reduced by a factor of 4 , but the RMSE on $U_{\mathrm{WB}}$ is still significant at $20 \mathrm{~cm} \mathrm{~s}^{-1}$, even if there is no error on the wind. Larger incidence angles also suffer from lower backscatter levels and thus a larger instrumental error in the raw line-ofsight velocity $U_{\text {LOS }}$.

A possible intermediate approach is to use a numerical wave model to estimate $U_{\mathrm{S}, \mathrm{R}}$, with typical errors ranging from 15 to $20 \%$ in open ocean and deepwater conditions according to Rascle and Ardhuin (2013). However, recent investigation by Ardhuin et al. (2017b) on the impact of ocean currents on small-scale sea-state variations suggests that it may be difficult to separate the gradients in wave bias from the surface current at scales under $100 \mathrm{~km}$.

Another more radical approach is to measure the sea-state properties necessary for the evaluation of $U_{\mathrm{S}, \mathrm{R}}$, in addition to the Doppler velocity $U_{\mathrm{LOS}}$. In general $U_{\mathrm{S}, \mathrm{R}}$ can be estimated from the directional wave spectrum. The details of this estimation with a rotating wave Doppler spectrometer, combining the ideas of Jackson et al. (1985) and Caudal et al. (2014), is presented in Appendix A. An overall accuracy of $10 \%$ for $U_{\mathrm{S}, \mathrm{R}}$ is expected from our preliminary algorithm.

\section{Restitution of the total surface velocity}

The algorithm proposed to retrieve the field of surface velocity vectors and wave spectra is summarized in Fig. 5. The elementary measured quantities are the power $P$ and velocity $U_{\text {LOS }}$ as a function of the range $r$ within each footprint of diameter $6 \mathrm{~km}$, with a resolution $d r$ that is determined by the $200 \mathrm{MHz}$ radar bandwidth giving $0.75 \mathrm{~m}$ along the line of sight, and less than $4 \mathrm{~m}$ projected on the horizontal for $\theta_{i}=12^{\circ}$. The range-averaged line-of-sight velocity is also given by the phase difference between pairs of pulses (Zrnic, 1977). This estimate requires a strong correlation between consecutive echoes in spite of rapid motion of the footprint, which calls for a relatively high pulse repetition frequency, and thus averaging over many pulses to reduce the random error on small phase shifts. We also note that the horizontal current contribution to $U_{\text {LOS }}$ occurs through the apparent vertical motion of the surface as waves are advected by the current (Nouguier et al., 2018). As a result, for depth-varying currents, the measured current corresponds to the advection velocity (Kirby and Chen, 1989) for waves contributing to the mean slope velocity. With our understanding of the instrument it does not appear feasible to estimate a possible vertical shear from the SKIM measurements that could oth-

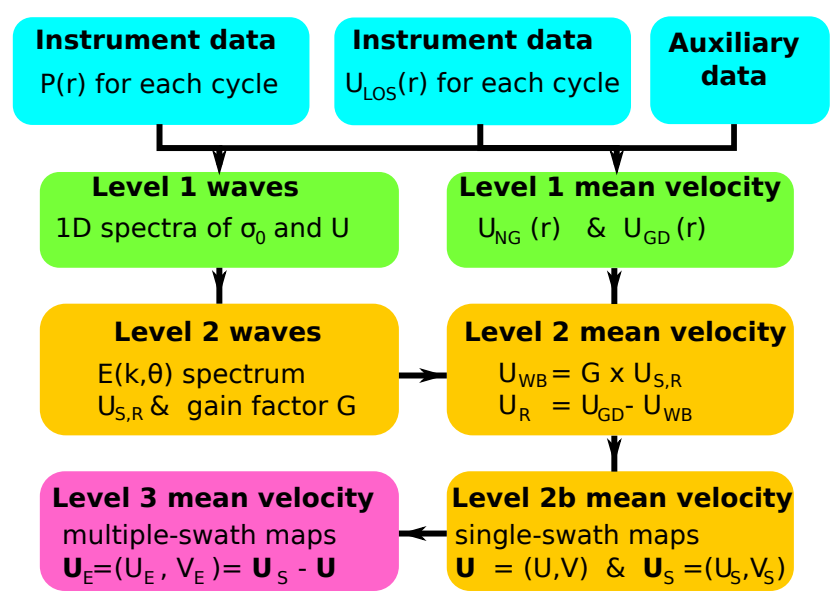

Figure 5. Logical tree going from Level 0 raw data to Level 3 gridded fields of surface velocity and wave parameters. For gridding with multiple satellite passes, we propose using the quasi-Eulerian surface velocity defined as $\mathbf{U}_{\mathrm{E}}=\mathbf{U}-\mathbf{U}_{\mathrm{S}}$ (Jenkins, 1989).

erwise be possible with the larger integration times of other measurement systems (e.g., Shrira et al., 2001).

In summary, the basic measurement are highly resolved in range but averaged over the footprint diameter in the perpendicular (azimuthal) direction. This averaging is the basic principle of the wave spectrometer laid out by Jackson et al. (1985). Namely, only the waves aligned with the line of sight produce a modulation of the signal in the range direction (see also Nouguier et al., 2018, Eq. 46).

Several effects introduce measurement errors. We have investigated the following three terms in the error budget for the level 2 data (radial current velocity $U_{\mathrm{R}}$ ) in particular:

- $\operatorname{err}_{\mathrm{DC}}$ : the Doppler centroid estimation error is a function of the strength of the radar backscatter, hence of the incidence angle, radar transmitted power, altitude and averaging. Using broad margins (e.g., using only half of the rated Ka-band power) this was estimated to be under $10 \mathrm{~cm} \mathrm{~s}^{-1}$ at $\theta_{i}=12^{\circ}$ and in the absence of ice (SKIM Team, 2017). This error is a well-known function of the azimuth relative to the satellite ground track.

- errPA: a $5 \mathrm{~cm} \mathrm{~s}^{-1}$ second error corresponds to a Doppler shift of $56 \mathrm{~Hz}$ that can be obtained by an error in elevation of $8 \times 10^{-5 \circ}$ (see Appendix B). However, such an error is easily detected thanks to the rotating beam. This is because any small mispointing that varies slowly in time produces a clearly identifiable pattern as a function of azimuth. This is detailed in Appendix B. As a result, with realistic attitude stability better than $2.7 \times 10^{-40}$ over $20 \mathrm{~s}$, we expect an RMSE contribution to the current error of a few $\mathrm{cm} \mathrm{s}^{-1}$. Our worst case scenario with random jumps of the attitude gave errors of $3 \mathrm{~cm} \mathrm{~s}^{-1}$. This error will be neglected in the following sections. 
Table 1. Summary of expected RMSEs for Level 2 radial velocity (for $\theta_{\mathrm{i}}=12^{\circ}$ ) and along-track Level $3 \mathrm{a}$ (single swath snapshot) or zonal Level $3 b$ (multi-swath time-evolving field) velocity component, based on the preliminary algorithms in the case of the SKIM2 configuration (open burst, eight beams). TBD stands for to be determined.

\begin{tabular}{|c|c|c|c|c|c|}
\hline Region & Equator & $\begin{array}{l}\text { Fram } \\
\text { (open } \\
\text { water) }\end{array}$ & $\begin{array}{l}\text { Fram } \\
\text { (ice) }\end{array}$ & $\begin{array}{l}\text { Gulf } \\
\text { Stream }\end{array}$ & $\begin{array}{l}\text { Oregon } \\
\text { coast }\end{array}$ \\
\hline $\begin{array}{l}\operatorname{err}_{\mathrm{DC}} \\
\text { errPA } \\
\text { errWB }\end{array}$ & $\begin{array}{l}<0.1 \mathrm{~m} \mathrm{~s}^{-1} \\
<0.03 \mathrm{~m} \mathrm{~s}^{-1} \\
0.05 \mathrm{~m} \mathrm{~s}^{-1}\end{array}$ & $\begin{array}{l}<0.1 \mathrm{~m} \mathrm{~s}^{-1} \\
<0.03 \mathrm{~m} \mathrm{~s}^{-1} \\
0.08 \mathrm{~m} \mathrm{~s}^{-1}\end{array}$ & $\begin{array}{l}<0.1 \mathrm{~m} \mathrm{~s}^{-1} \\
<0.03 \mathrm{~m} \mathrm{~s}^{-1} \\
0.02 \mathrm{~m} \mathrm{~s}^{-1}\end{array}$ & $\begin{array}{l}<0.01 \mathrm{~m} \mathrm{~s}^{-1} \\
<0.03 \mathrm{~m} \mathrm{~s}^{-1} \\
0.15 \mathrm{~m} \mathrm{~s}^{-1}\end{array}$ & $\begin{array}{l}<0.01 \mathrm{~m} \mathrm{~s}^{-1} \\
<0.03 \mathrm{~m} \mathrm{~s}^{-1} \\
0.13 \mathrm{~m} \mathrm{~s}^{-1}\end{array}$ \\
\hline $\begin{array}{l}\text { L3a, } L_{\mathrm{e}} \\
\text { L3a error }\end{array}$ & $\begin{array}{l}89 \mathrm{~km}^{-1} \\
0.03 \mathrm{~m} \mathrm{~s}^{-1}\end{array}$ & $\begin{array}{l}59 \mathrm{~km}^{-1} \\
0.11 \mathrm{~m} \mathrm{~s}^{-1}\end{array}$ & $\begin{array}{l}\text { TBD } \\
\text { TBD }\end{array}$ & $\begin{array}{l}65 \mathrm{~km} \\
<0.09 \mathrm{~m} \mathrm{~s}^{-1}\end{array}$ & $\begin{array}{l}90 \mathrm{~km}^{-1} \\
0.04 \mathrm{~m} \mathrm{~s}^{-1}\end{array}$ \\
\hline $\begin{array}{l}\text { L3b, } L_{\mathrm{e}} \\
\text { L3b error }\end{array}$ & $\begin{array}{l}290 \mathrm{~km}^{-1} \\
0.14 \mathrm{~m} \mathrm{~s}^{-1}\end{array}$ & $\begin{array}{l}62 \mathrm{~km}^{-1} \\
0.12 \mathrm{~m} \mathrm{~s}^{-1}\end{array}$ & $\begin{array}{l}\text { TBD } \\
\text { TBD }\end{array}$ & $\begin{array}{l}71 \mathrm{~km}^{-1} \\
0.23 \mathrm{~m} \mathrm{~s}^{-1}\end{array}$ & $\begin{array}{l}95 \mathrm{~km} \\
0.09 \mathrm{~m} \mathrm{~s}^{-1}\end{array}$ \\
\hline
\end{tabular}

- errwB: the wave bias error is explained and justified in Appendix A. We have performed a detailed analysis on the error $\operatorname{err}\left(U_{\mathrm{S}, \mathrm{R}}\right)$ in the estimation of the radial Stokes drift $U_{\mathrm{S}, \mathrm{R}}$ over each footprint, which contributes to errwB amplified by the $G$ factor. Errors in the estimation of the $G$ factor are not so easy to model but, for a given mean square slope, $G$ is expected to have a weak dependence on sea-state properties and it is related to the ratio of the Doppler and $\sigma_{0}$ spectra. We have therefore assumed that errors on the estimation of $G$ should not cause a larger error than that due to uncertainties in $U_{\mathrm{S}, \mathrm{R}}$. Hence we used err $\mathrm{WB}_{\mathrm{WB}}=2 G \operatorname{err}\left(U_{\mathrm{S}, \mathrm{R}}\right)$.

We have not considered the particular cases of extremely low backscatter, for wind speeds under $2 \mathrm{~m} \mathrm{~s}^{-1}$, in which the three errors can be correlated, and we have assumed that these three error sources are uncorrelated.

\section{Overall performance and effective resolution}

\subsection{From radial components to gridded vector fields}

Here we show results corresponding to one particular setup of the SKIM radar, which is called "SKIM2" (see SKIM Team, 2017, for details). This configuration uses eight beams, with one beam at nadir $\left(\theta_{i}=0\right)$, two beams at $6^{\circ}$ and five beams at $12^{\circ}$. These beams make 3.14 rotations $\min ^{-1}$ (one turn in $17.5 \mathrm{~s}$ ) thanks to the rotation of a plate carrying feed horns arranged as shown in Fig. 6a.

The horns are placed around the focal point of a parabolic reflector, similar to the wave scatterometer SWIM of the China-France Ocean Satellite (CFOSAT) mission (Hauser et al., 2017). The main differences between SWIM and SKIM are the radar frequency (Ka-band instead of Ku-band, giving smaller footprints), and the Doppler capability of SKIM. Using incidence angles up to $12^{\circ}$ and altitude of $695 \mathrm{~km}$ gives swath width of $270 \mathrm{~km}$ as shown in Fig. $6 \mathrm{~b}$.
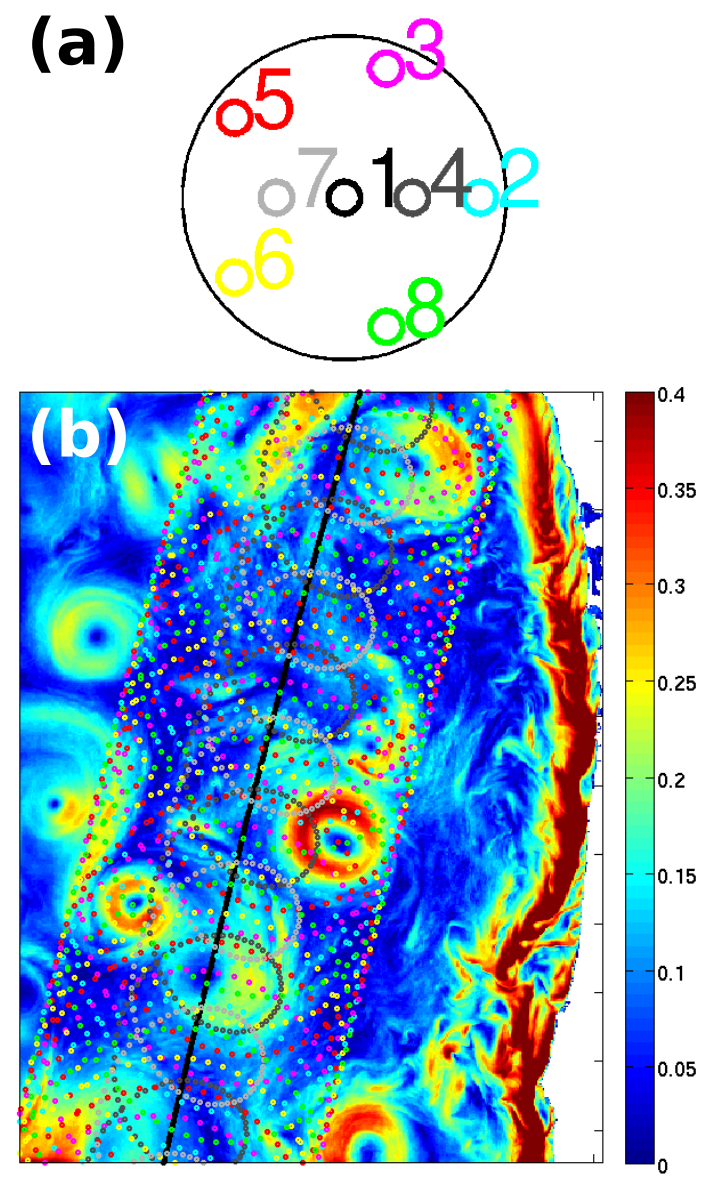

Figure 6. (a) Pattern of beams ( 1 is at nadir, 4 and 7 are at $6^{\circ}$, the others at $12^{\circ}$ incidence). The different colors help associating the footprint patterns in (b) with each beam. Background colors in (b) represent simulated current velocities off the Oregon coast (in $\mathrm{m} \mathrm{s}^{-1}$ ), courtesy of Y. Chao, previously used by Fu and Ubelmann (2014) for the evaluation of the SWOT mission performance. 


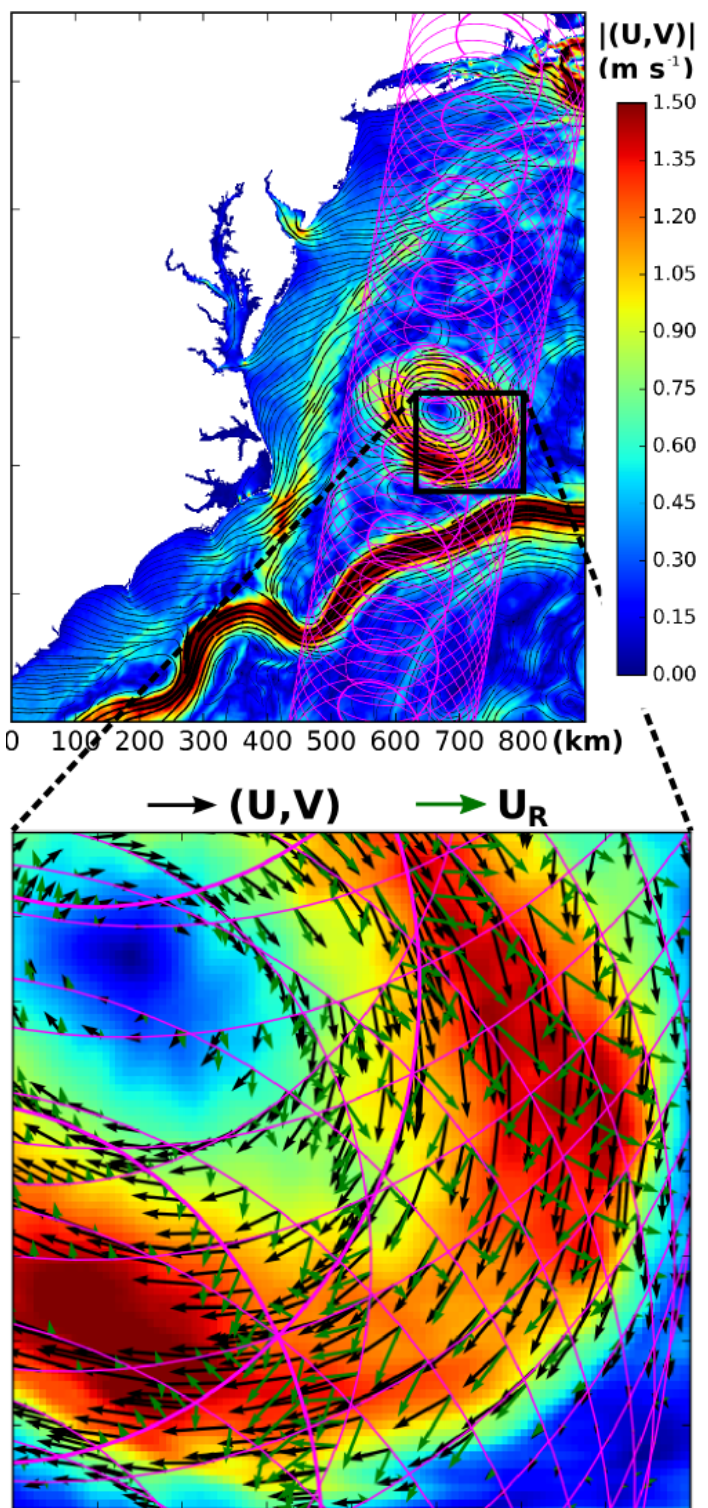

Figure 7. Illustration of current components $U$ and $V$ and radial component $U_{\mathrm{R}}$ in the case of the Gulf Stream.

For each beam this gives measurement cycles of 1024 pulses each. The radar pulse repetition frequency is $32 \mathrm{kHz}$. The line-of-sight velocity is determined from the phase shift between consecutive pulses. These parameters define the instrument error err ${ }_{\mathrm{DC}}$, as listed in Table 1.

The other important source of error, caused by inaccuracies in the wave bias correction is a function of the beam geometry but also of the strength of gradients of the Stokes drift, which are mostly caused by current gradients (Ardhuin et al., 2017b). This wave bias error is estimated following the method laid out in Appendix A.

Finally, the last important source of error we have investigated is the mapping error, going from Level 2 data at each footprint to Level 3 data on a regular grid. This mapping er-

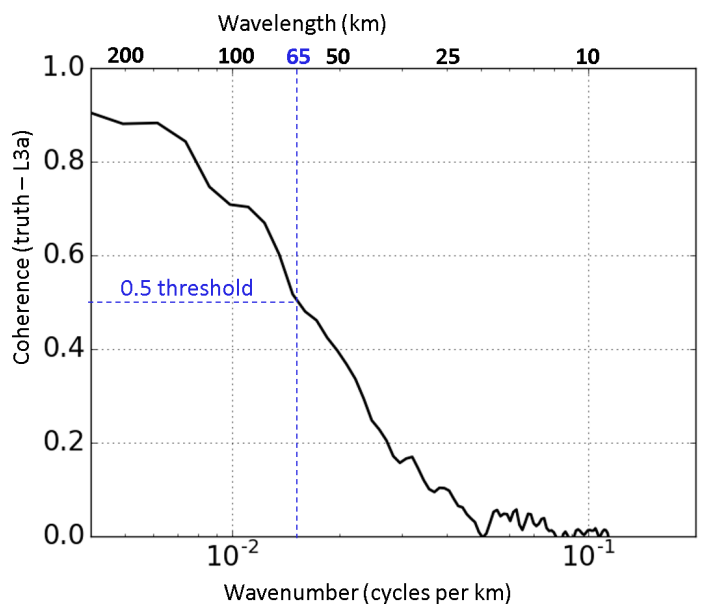

Figure 8. Average coherence of simulated SKIM Level 3a current with the "truth" provided by MITgcm simulations, in the case of the Gulf Stream, for October 2011.

ror is similar to what happens with HF radars (e.g., Lipa and Barrick, 1983; Kim et al., 2008). In particular, SKIM only measures radial components so that on the edges of the swath only the cross-track component is measured, and in the center there are only measurements of the along-track component, as shown in Fig. 7.

The use of the two incidence angles, 6 and $12^{\circ}$, allows us to fill the swath and obtain cross-track measurements closer to the center of the swath. We can also use the nadir altimeter beam to obtain cross-track geostrophic velocities. An optimal interpolation method specially designed to include covariances between the two current components has been adapted to also include this additional nadir data (SKIM Team, 2017).

The combination of these three errors gives the total error that must be compared to the magnitude of the current. We have therefore defined an effective resolution wavelength $L_{\mathrm{e}}$ as the scale above which the total error is larger than the signal, as shown in Fig. 8 for the case of the Gulf Stream.

The overall error depends on many factors related to the patterns in ocean currents and the instrument parameters. We have estimated all errors, in particular those of ocean conditions, using state-of-the-art models for the ocean circulation (e.g., Rocha et al., 2016; Gula et al., 2015) and associated ocean waves (Roland and Ardhuin, 2014; Ardhuin et al., 2017b). Model simulations were performed at resolutions on the order of $1.5 \mathrm{~km}$ for a set of regions for which we expect SKIM to have a strong contribution, resolving processes that are not accessible with today's observing systems. These include an Arctic region with strong currents (Fram Strait), an equatorial region (in the Atlantic around $23^{\circ} \mathrm{W}$ ), a western boundary current (the Gulf Stream) and a coastal region (Oregon).

The RMSE on current components and the resulting effective resolution are summarized in Table 1, but they are better understood by comparing maps of currents from the 


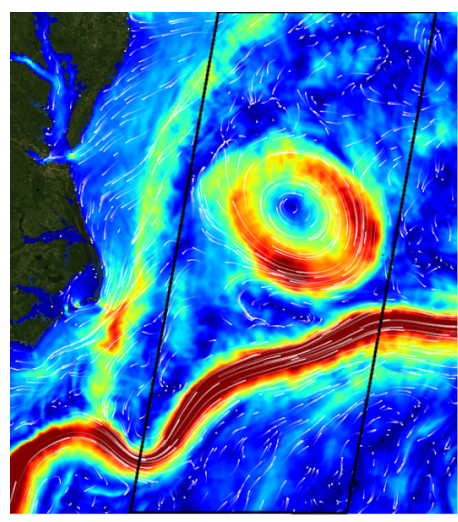

(a) Modeled current

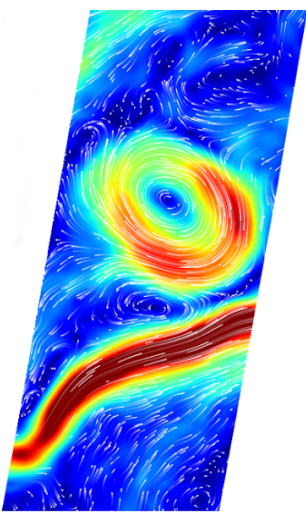

(b) SKIM L3A
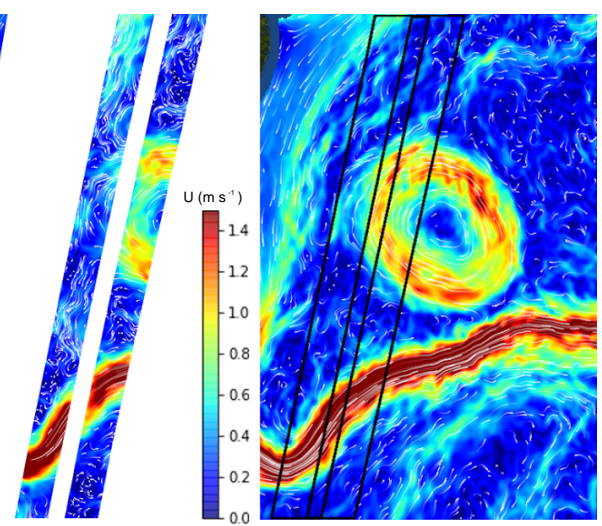

(c) SWOT

(d) Current from SSH

Figure 9. Simulated ocean currents over the Gulf Stream, and associated SKIM and SWOT simulated observations for a single satellite pass.

simulated SKIM processing to the input modeled currents. Several examples are given by SKIM Team (2017). It is also interesting to compare the results of different observing systems. An important outcome of the SKIM simulations is that a wide swath is necessary to obtain the shorter revisit time needed to monitor the smaller ocean structures that evolve more rapidly.

Interferometric SAR technology will be used to produce a $120 \mathrm{~km}$ wide swath for the Surface Water Ocean Topography (SWOT) mission (see Fig. 9). The narrower swath gives a larger revisit time at mid-latitudes of 10 days with SWOT instead of 4 days with SKIM. As a result, only largerscale motion can be monitored with SWOT, with an effective wavelength of $L_{\mathrm{e}}=115 \mathrm{~km}$ in the Gulf Stream region, instead of $71 \mathrm{~km}$ with SKIM. The Doppler scatterometer mission proposed by Bourassa et al. (2016) has a much wider swath, about $1800 \mathrm{~km}$, and is designed to measure wind and current vectors. Because it measures at larger incidence angles, for which signals are weaker, an accurate current estimate requires averaging over several passes, thereby reducing the effective temporal resolution. As a result, this is a great instrument for vector wind measurements but it is not clear if it would perform better than SKIM for current measurements.

In the case of SWOT, the interpretation of the sea surface height ( $\mathrm{SSH}$ ) in terms of current relies on the geostrophic equilibrium. Unbalanced motion, such as internal waves, also contribute to the SSH. As a result this simple interpretation of the SSH contains small-scale noise associated with ageostrophic motion, shown in Fig. 9c and d. The separation of balanced and unbalanced motion is the topic of active research (e.g., Ponte et al., 2017). Further improvements in the restitution of temporal evolution, and thus the reduction for $L_{\mathrm{e}}$ for L3b products from both SWOT and SKIM, will benefit from dynamic methods which are under development (Ubelmann et al., 2016).

\subsection{Challenges and opportunities over sea ice}

With the expected widening of the marginal ice zone (MIZ) in the Arctic (e.g., Aksenov et al., 2017), this expanding and important region of the world ocean will not be well monitored in terms of currents by existing and planned satellite missions.

Ice concentration is the only parameter that is well monitored near the ice edge, with difficulties in recovering ice thickness and ice drift (Korosov and Rampal, 2017). The very rich dynamics across the ice edge offer great opportunities for Doppler-based measurements. In particular, narrow ice jets and eddies are observed in satellite imagery (Johannessen et al., 1983) and reproduced in high-resolution models (Horvat et al., 2016).

These features cannot be monitored by today's altimetry due to their small scale and the changes in waveform shapes from open water to ice. In the ice, the wave-induced bias becomes negligible as the wave amplitude is strongly attenuated. On the contrary, the instrument noise is expected to increase by about a factor of 2.5 due to a generally weaker $(8 \mathrm{~dB})$ backscatter over ice compared to open ocean at incidence angles under $12^{\circ}$ (SKIM Team, 2017). A detailed analysis of errors right at the ice edge requires taking into account the strong variation in backscatter in all terms of the error budget. This is beyond the scope of the present paper.

Also, it should be possible to measure waves in ice without the SAR processing used by Ardhuin et al. (2017a), but by using the Doppler spectrum and the modulation due to range bunching. Indeed, it is not clear how strong the tilt modulation is over the ice, but range bunching is maximum for a swell steepness $k a=\tan \theta_{i}$, which is 0.1 for $\theta_{i}=6^{\circ}$. A swell steepness of 0.025 , as in the MIZ observations reported by Sutherland and Gascard (2016), still produces a $20 \%(0.9 \mathrm{~dB})$ modulation of $\sigma_{0}$. 


\section{Preliminary study of surface current impact}

In order to evaluate the contribution of a surface Doppler measurement in an ocean forecasting system, we have used the TOPAZ assimilation system, implemented in the Copernicus Arctic Marine Forecasting Center. This system uses a regional configuration of the HYCOM ocean model over the North Atlantic and Arctic Oceans - without tides - and assimilates different types of satellite and in situ observations with an ensemble Kalman filter (EnKF), running 100 dynamic members.

Each ensemble member receives random perturbations of the ocean surface conditions, including non-divergent random winds with an amplitude of $2.5 \mathrm{~m} \mathrm{~s}^{-1}$ (see Xie et al., 2017, for more information about the reanalysis). We have used the simulated uncertainties of SKIM Level 2 surface velocities, following their description above, to produce a measure of the impact of assimilating SKIM surface currents in conjunction with all other observations on a typical weekly cycle of the TOPAZ reanalysis in May 2015, in a period of stable reanalysis operations following 24 years of data assimilation.

We measure the information content of the assimilated data using the degrees of freedom for signal (DFS; Cardinali et al., 2004). This DFS has a maximum value of 100 in the case of the EnKF used in TOPAZ. Target DFS values range from 0 to 10 , above which there is a risk of "overassimilation" (Sakov et al., 2012). The observation impact is calculated for each grid cell, using knowledge of the space and time location of the observations and their uncertainty estimates, but not the actual observed values. Since all observations are assimilated jointly, the impact of one observation type reduces that of the other types. The DFS values are dependent on the background and observation uncertainties specified in the TOPAZ system and are different in a different ocean data assimilation system.

Figure 10 exhibits the DFS values obtained by assimilating simulated SKIM surface currents together with other real measurements. The highest DFS appears in frontal regions like the Equatorial Counter Current, the Gulf Stream and the Azores Current. The area near the Equator shows particularly high values as the impact of traditional altimeter data is limited by the vanishing of the Coriolis force. The South Atlantic is artificially removed as the simulated SKIM data used here only covers the North Atlantic.

The DFS values indicate that SKIM provides the second largest impact overall, and the largest information content in the Gulf Stream and Equatorial regions for ocean data assimilation. It may seem counterintuitive that the impact of surface currents from SKIM exceeds the impact of depthaveraged currents as measured with traditional altimeters in the Gulf Stream. This could be a transient effect due to the first-time assimilation of SKIM: the ensemble variance of surface currents may diminish in the following assimilation cycles and the DFS values diminish accordingly. Alterna- tively it could be due to our assumption of negligible representativity errors.

The results presented here only utilize the surface currents, not yet the surface waves or the sea ice drift from SKIM. This observing system simulation experiment (OSSE) is highly simplified and does not resolve complex feedbacks of repeated data assimilation cycles. Still, this OSSE indicates that there is a scope for assimilation of sea surface currents in an operational forecasting system and that SKIM data should provide relevant information that is independent of existing ocean observations.

\section{Conclusions and perspectives}

Using nadir and near-nadir radar beams with Doppler measurements, the Sea surface KInematics Multiscale monitoring (SKIM) mission is designed to measure surface velocity vectors and ocean wave spectra. Measuring wave spectra down to wavelengths of $20 \mathrm{~m}$ and possibly less makes it possible to estimate the surface Stokes drift vector and correct for a strong wave-induced bias in the surface velocity vector, which is on the order of a gain coefficient $G$ times the surface Stokes drift.

The use of a rotating beam pattern is critical in reducing errors caused by knowledge uncertainties in the platform attitude, which is today the main source of error in the level 2 surface current derived from the Sentinel 1 SAR constellation. Here we presented a performance analysis using the orbit of Sentinel-1C (S1C), except for a $4^{\circ}$ shift to the east. This is a Sun-synchronous orbit, with $98.2^{\circ}$ inclination, $693 \mathrm{~km}$ altitude and 12-day repeat cycle. This geometry gives a swath width of $270 \mathrm{~km}$ and a relatively large signal-to-noise ratio thanks to the higher backscatter at these low incidence angles. The incidence angle of SKIM is limited to $12^{\circ}$ by the choice of antenna technology that uses a rotating horn plate and fixed parabolic reflector. With this configuration, larger incidences lead to beam distortions. The $4^{\circ}$ shift allows for a large overlap between SKIM and S1C on ascending tracks that could be useful for calibration purposes. Other choices in synergy with altimeters or radiometers could justify a higher altitude, allowing for a wider swath at the price of a lower signal-to-noise ratio for the radar-detected power.

Compared to the Envisat C-band measurements at incidence angles of $30^{\circ}$ used by Rouault et al. (2010), in which case $G \simeq 12$, the error on the wave bias is expected to be reduced by a factor of 4 or more, allowing single-pass estimation of the current components with an accuracy on the order of $0.1 \mathrm{~m} \mathrm{~s}^{-1}$ for a wavelength of about $60 \mathrm{~km}$.

When the radial components are combined to produce maps of gridded vector velocity, the effective wavelength resolved, at which the signal is above the noise level, is on the order of 60 to $90 \mathrm{~km}$ for a single swath, depending on the pattern of currents. Except for latitudes 78 to $83^{\circ}$ where the revisit time is less than 1 day, the effective resolution is de- 

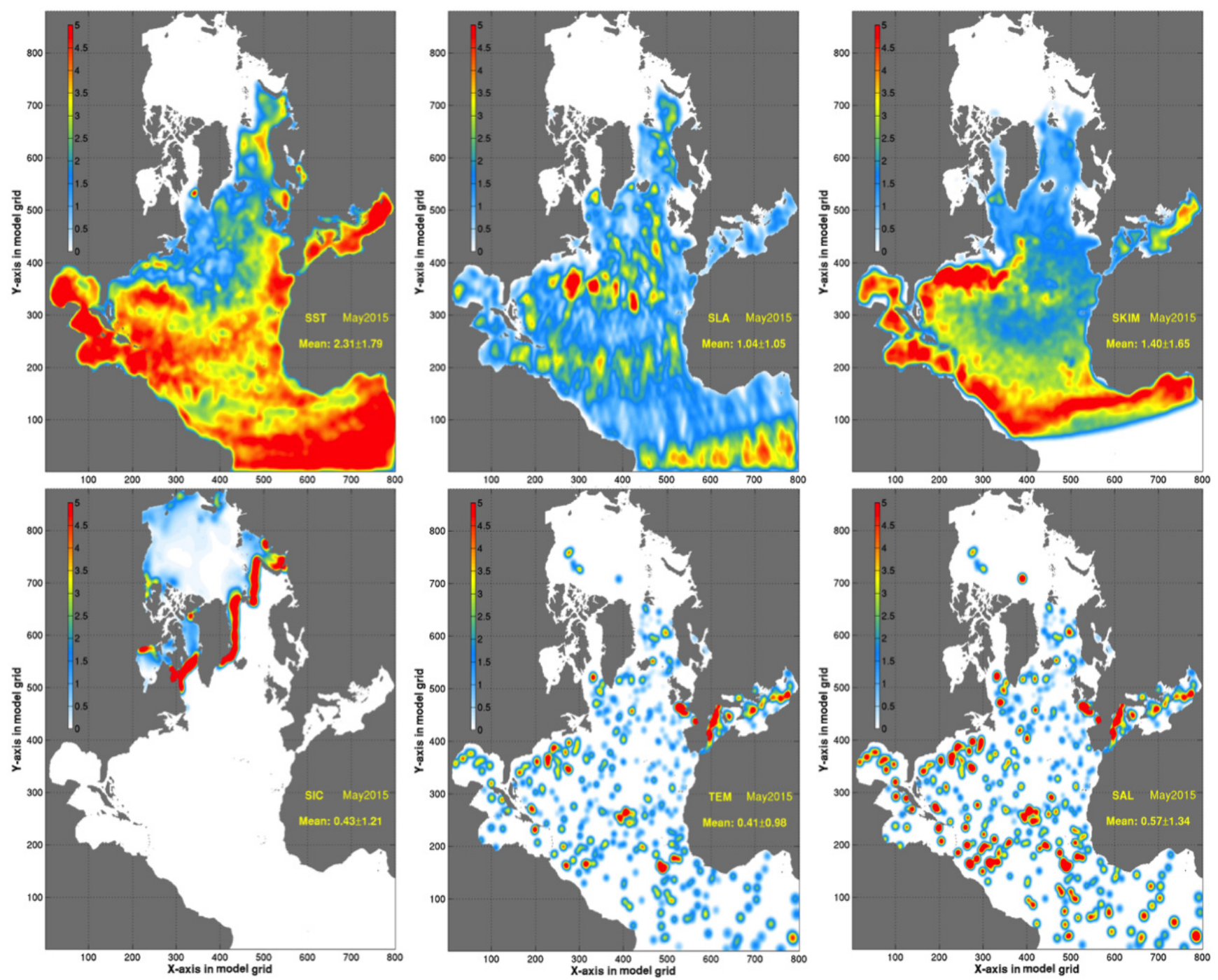

Figure 10. Degrees of freedom for signal of all assimilated observations over 1 week in May 2015. Top row from left to right: OSTIA sea surface temperature, CMEMS delayed-mode altimeter tracks and SKIM sea surface. Bottom row from left to right: OSI SAF sea ice concentrations and in situ (including Argo) temperature and salinity profiles.

graded when the time evolution of the currents is considered. At mid-latitudes this gives $70<L_{\mathrm{e}}<100 \mathrm{~km}$, due to the 3 day revisit time.

Further improvement on the accuracy and effective resolution may come from many improvements in radar settings (e.g., use of full power instead of $50 \%$, evolution in amplifier technology) which could give larger transmitted power and reduce the instrument noise err DC. Another source of improvement will be the reduction of wave bias error $\operatorname{err}_{\mathrm{WB}}$, in which our estimation of the $G$ factor error may well be overestimated, and a combined analysis or assimilation of waves and currents could properly take into account the correlations of waves and currents and lead to more accurate current estimates. Hence the error level and resolution found in our simulations are probably conservative.
Our results clearly show that Doppler oceanography from space can be a very useful technique for monitoring spaceand timescales of the ocean currents that are not well observed today. Future altimeter designs should probably consider adding off-nadir rotating beams for more effective coverage of the ocean. In the present paper we have not discussed much the added benefits of ocean wave measurements with unprecedented spectral and spatial coverage. These will be discussed in other publications. We only point out here that the sea-state variability at small scales is probably dominated by the effect of ocean currents (Ardhuin et al., 2017b). It is thus logical to measure waves and currents together, and possibly further use the measured variability of sea-state parameters to further constrain the magnitude of current gradients. 
Code and data availability. Numerical model results presented in this article are available via ftp at ftp://ftp.ifremer.fr/ifremer/ww3/ HINDCAST/OTHER/SKIM/. 
Appendix A: Estimation of wave-induced bias $U_{\mathrm{WB}}$ from directional wave data

One important difficulty for the estimation of $U_{\mathrm{S}, \mathrm{R}}$ by projecting Eq. (3) in direction $\theta$ is that the Stokes drift contains contributions from all directions $\theta^{\prime}$, whereas the measurement on a single footprint only gives contributions in the look direction $\theta$. For each footprint in azimuth $\theta^{\prime}$ we only have the contribution of the waves propagating in direction $\theta^{\prime}$, which we define as

$$
\begin{aligned}
U_{\mathrm{S}, 1 \mathrm{D}}\left(\theta^{\prime}\right) & =2 \sqrt{g} \int_{0}^{k_{\max }} k^{1.5} E\left(k, \theta^{\prime}\right) \mathrm{d} k \\
& +F\left(k_{\max }, \theta^{\prime}\right) E\left(k_{\max }, \theta^{\prime}\right),
\end{aligned}
$$

where $k_{\max }$ is the wavenumber of the shortest resolved waves. Assuming that the spectrum of shorter wave rolls off like $k^{3}$ and neglecting non-linear effects gives $F\left(k_{\max }\right.$, $\left.\theta^{\prime}\right)=\sqrt{g} k_{\max }^{2.5}$. Using hourly averaged measured spectra at station PAPA, this gives a typical random error of $6 \%$ if $k_{\max }$ corresponds to a $20 \mathrm{~m}$ wavelength. The general broadening of the directional spectrum towards high frequency gives a weaker importance of shorter waves (e.g., Peureux et al., 2018).

Given that the wave spectrum varies both along the sea surface and with directions, we have to interpolate either in spectral space (from $\theta$ to $\theta^{\prime}$ ) or in physical space ( $x$ and $y$ ). Simulations indicate that variations in physical space are less severe than those in directions, as illustrated in Fig. A1, over a Gulf Stream ring where the Stokes drift is enhanced by wind blowing against the current. We thus estimate $U_{\mathrm{S}, \mathrm{R}}$ using

$U_{\mathrm{S}, \mathrm{R}}(x, y, \theta) \simeq \sum \cos \left(\theta-\theta^{\prime}\right) U_{\mathrm{S}, 1 \mathrm{D}}\left(x^{\prime}, y^{\prime}, \theta^{\prime}\right) \Delta_{\theta}^{\prime}$,

where the sum is over all directions and the approximation is due to the fact that the location $(x, y)$ is different from $\left(x^{\prime}\right.$, $\left.y^{\prime}\right)$ where the contribution $U_{\mathrm{S}, 1 \mathrm{D}}\left(x^{\prime}, y^{\prime}, \theta^{\prime}\right)$ is measured. In practice we use the locations $\left(x^{\prime}, y^{\prime}\right)$ that are closest to $(x, y)$, separated by a distance $r\left(\theta^{\prime}\right)$.

The variations of $U_{\mathrm{S}, 1 \mathrm{D}}\left(\theta^{\prime}\right)$ over the distance $r\left(\theta^{\prime}\right)$, which is typically less than $50 \mathrm{~km}$, is mostly due to the effect of currents on waves (Ardhuin et al., 2017b).

In our simulations we have also varied the beam rotation speed, number of beams and number of azimuths per rotation. Because these parameters give different locations of footprints we have used an approximation of the radial Stokes drift $U_{\mathrm{S}, \mathrm{R}}$ from the map of Stokes drift vectors instead of the full directional spectrum, this is

$U_{\mathrm{S}, \mathrm{R}}(x, y, \theta) \simeq \frac{2}{\pi} \sum U_{\mathrm{S}, \mathrm{R}}\left(x^{\prime}, y^{\prime}, \theta^{\prime}\right) \cos \left(\theta-\theta^{\prime}\right) \Delta_{\theta}^{\prime}$,

where the sum is over angles $\theta-\pi / 2<\theta^{\prime}<\theta+\pi / 2$ and the nearest available footprints with these azimuths are taken.

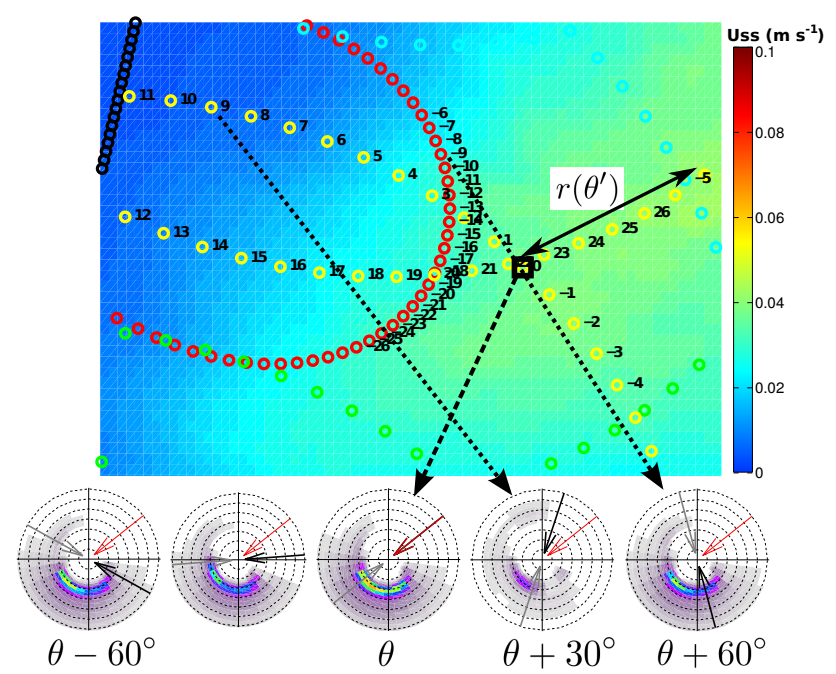

Figure A1. Illustration of the use of cycles in azimuth $\theta^{\prime}$ (circles) for the estimation of the wave bias $U_{\mathrm{WB}}=G U_{\mathrm{S}, \mathrm{R}}$ at the location (black square) of cycle with direction $\theta$. The background color shows the magnitude of $U_{\mathrm{S}}$, and the bottom spectra are at the location of different cycles, with wave energy plotted in the direction from which it arrives. In each spectra the red arrow is direction $\theta$, and the black and grey arrows show $\theta^{\prime}$ and $\theta^{\prime}+\pi$. The distance $r\left(\theta^{\prime}\right)$ is a source of error.

Equation (A3) relies on the assumption of small variability of the vector $\left(\boldsymbol{U}_{\mathrm{S}}, \boldsymbol{V}_{\mathrm{S}}\right)$ on the scale of the beam rotation. Indeed, $U_{\mathrm{S}, \mathrm{R}}(\theta)$ is the projection of $\left(U_{\mathrm{S}}, V_{\mathrm{S}}\right)$ in direction $\theta$. If $\left(U_{\mathrm{S}}\right.$, $\left.V_{\mathrm{S}}\right)$ is uniform in space then $U_{\mathrm{S}, \mathrm{R}}=\left|U_{\mathrm{S}}, V_{\mathrm{S}}\right| \cos \left(\theta-\theta_{0}\right)$, with $\theta_{0}$ the direction of the Stokes drift vector.

We have performed realistic high-resolution simulations in a wide range of conditions: Oregon coast, Gulf Stream, equatorial currents, Fram strait and Agulhas Current. Based on all these simulations and assuming a constant $G$, we find that the error err ${ }_{\mathrm{WB}}$ on the estimation of $U_{\mathrm{WB}}$, has a negligible bias and a standard deviation that is on the order of

$\mathrm{SD}\left(\operatorname{err}_{\mathrm{WB}}\right) \simeq \varepsilon G \mathrm{SD}\left(U_{\mathrm{S}}\right) r_{2} / 20 \mathrm{~km}$,

where $\varepsilon$ is a non-dimensional factor which ranges from 0.10 in the case of the Equator near $23^{\circ} \mathrm{W}$ to 0.18 in the Gulf Stream case. $\mathrm{SD}\left(U_{\mathrm{S}}\right)$ is the standard deviation of the Stokes drift magnitude over the region that contribute to $U_{\mathrm{S}, \mathrm{R}}$ using Eq. (A2).

$r_{2}=\sqrt{\sum\left[r\left(\theta^{\prime}\right) \cos \left(\theta-\theta^{\prime}\right)\right]^{2} / N}$

is the root mean square distance over the $N$ cycles with directions $\theta^{\prime}$ that contribute to the estimation of $U_{\mathrm{S}, \mathrm{R}}(\theta)$, between the position of the footprint for azimuth $\theta$ and the footprints for $\theta^{\prime}$ weighted by $\cos \left(\theta^{\prime}-\theta\right)$. Hence, in the open ocean $r_{2}$ is completely specified by the geometry of the footprints, itself given by the rotation speed of the horn plate and the number of beams. In the case presented here $r_{2}$ is close to $20 \mathrm{~km}$ for the $12^{\circ}$ beams, and $15 \mathrm{~km}$ for the $6^{\circ}$ beams. 


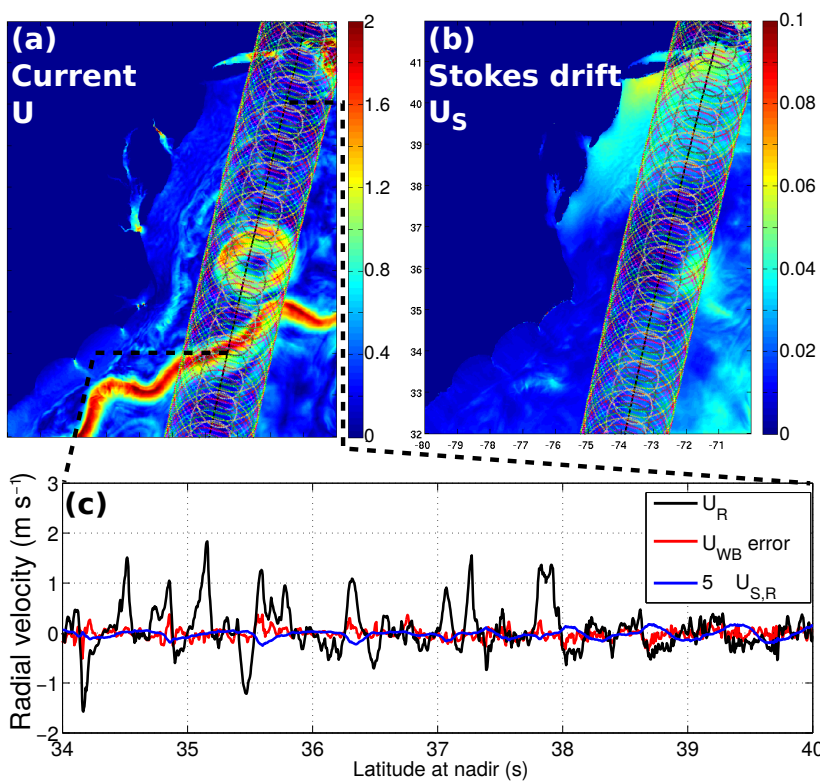

Figure A2. Example of (a) current in the Gulf Stream and associated (b) Stokes drift and (c) errors for the estimation of $U_{\mathrm{WB}}$ for beam $8\left(12^{\circ}\right.$ incidence, green circles in $\mathbf{a}$ and $\left.\mathbf{b}\right)$. In this example the standard deviation of errWB is $10 \mathrm{~cm} \mathrm{~s}^{-1}$, which is on the order of $5 U_{\mathrm{S}, \mathrm{R}}$. Note that the measured geophysical Doppler is $U_{\mathrm{GD}}=U_{\mathrm{WB}}+G U_{\mathrm{S}, \mathrm{R}}$ with $G \simeq 25$.

In order to take into account the variability of $G$ and random errors in the estimation of the wave spectrum, we have used an error twice as large as given by Eq. (A4).

The error err ${ }_{\mathrm{WB}}$ has smaller scales than both $U_{\mathrm{R}}$ and $U_{\mathrm{S}, \mathrm{R}}$, as shown in Fig. A2. The largest errors are associated with current gradients. This suggests that using some knowledge on wave-current interactions could lead to smaller errors.

\section{Appendix B: Attitude restitution using antenna rotation}

The non-geophysical contribution to the Doppler centroid frequency $\left(f_{\mathrm{NG}}\right)$ arises from the acquisition geometry (satellite attitude and instrument pointing) and the platform velocity. This frequency is much higher than the geophysical frequency, and it must be estimated carefully. Its theoretical expression is given by Raney (1986)

$$
\begin{aligned}
f_{\mathrm{NG}}= & \frac{2 V_{\mathrm{sc}}}{\lambda} \sin \gamma \cos \theta \\
& \times\left[1-\frac{\omega_{\mathrm{e}}}{\omega}(\epsilon \cos \beta \sin \Psi \tan \theta+\cos \Psi)\right] \\
& +\frac{2 V_{\mathrm{sc}}}{\lambda} e \cos \gamma \frac{\sin (\beta-p)}{\sqrt{1+e^{2}+2 e \cos (\beta-p)}},
\end{aligned}
$$

where $\lambda \simeq 8 \mathrm{~mm}$ is the radar wavelength, $V_{\mathrm{sc}}$ is the spacecraft velocity, $\gamma$ is the elevation angle, $\theta$ is the azimuth angle, $\epsilon$ is equal to 1 if $\theta \in[0,-\pi]$ and -1 otherwise, $\omega_{\mathrm{e}}$ is the angular rotation rate of the Earth, $\omega$ is the angular rotation rate of

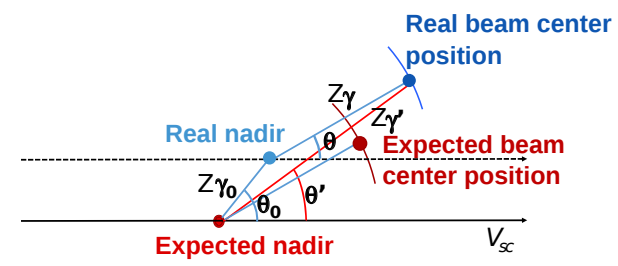

Figure B1. Definition of mispointing geometrical parameters $\gamma_{0}$ and $\theta_{0}$. We recall that $Z$ is the satellite altitude.

the spacecraft, is $\Psi$ the angular position on the orbit, $e$ is the eccentricity of the orbit and $p$ the argument of the perigee.

All the parameters of $f_{\mathrm{NG}}$ are well known except for uncertainties in the azimuth $\theta$ and the elevation $\gamma$ of the radar beam, due the imperfect knowledge of the satellite attitude. As given by Eq. (B2), the azimuth and elevation are perturbed by a tilt $\gamma_{0}$ that is maximum for the azimuth $\theta_{0}$ relative to the ground-track azimuth. These angles are defined in Fig. B1.

We have assumed the following:

- The antenna rotation speed is very well known and very stable (it can also be re-estimated after launch on a regular basis).

- The satellite attitude varies slowly (a preliminary re-

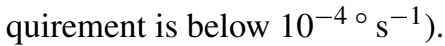

- Instrument noise is not correlated in time (pure white noise) and then is uncorrelated with any satellite attitude variation. It is therefore not considered here.

Hence $\gamma_{0}$ and $\theta_{0}$ define the difference between the expected and the real nadir position projected on the ground introduced by the satellite attitude misknowledge, so that $\gamma^{\prime}$ and $\theta^{\prime}$ are the parameter to be used instead of $\gamma$ and $\theta$ in Eq. (B1). It is very important to note that the $\gamma_{0}$ and $\theta_{0}$ parameters can vary in time. These time variations describe the satellite attitude misknowledge changes.

Provided that $\gamma_{0} / \gamma \ll 1$ then

$\gamma^{\prime}=\gamma+\gamma_{0} \cos \left(\theta-\theta_{0}\right)$

$\theta^{\prime}=\theta-\gamma_{0} \sin \left(\theta-\theta_{0}\right)$.

The Doppler shift residue $\delta f_{\mathrm{NG}}\left(\gamma_{0}, \theta_{0}\right)$ induced by the satellite attitude misknowledge is computed using Eqs. (B1) and (B2).

The situation is better understood by using the fact that $e \ll 1$ and $\omega_{\mathrm{e}} / \omega \ll 1$, leading to simplified equation

$$
\begin{aligned}
\Delta f_{\mathrm{NG}}\left(\gamma_{0}, \theta_{0}\right) & \approx \frac{2 V_{\mathrm{sc}}}{\lambda} \gamma_{0} \\
& {\left[\cos \gamma \cos \theta \cos \left(\theta-\theta_{0}\right)\right.} \\
& \left.+\sin \gamma \sin \theta \sin \left(\theta-\theta_{0}\right)\right] .
\end{aligned}
$$

In our case, $\gamma<12^{\circ}, \Delta f_{\mathrm{NG}}\left(\gamma_{0}, \theta_{0}\right)$ is dominated by the term $\cos \gamma \cos \theta \cos \left(\theta-\theta_{0}\right)$ that contains only twice the beam rotation frequency as shown in Fig. B2. 
For example, looking at the black curve in Fig. B2, a positive tilt $\gamma_{0}$ in direction $\theta_{0}=0$ gives the same positive Doppler anomaly when looking forward along the track $(\theta=0)$ when the Doppler is positive and $\gamma^{\prime}=\gamma+\gamma_{0}$, and backward $\theta=180^{\circ}$ when the Doppler is negative and $\gamma^{\prime}=\gamma-\gamma_{0}$.

The pointing knowledge that is provided by the complete system (including SKIM, star trackers, etc.; around $0.2^{\circ}$ in elevation and $0.5^{\circ}$ in azimuth) is not sufficient to get accurate retrieval of $f_{\mathrm{NG}}$. As shown in Fig. B2, a tilt $\gamma_{0}$ of only $0.003^{\circ}$ gives errors in the retrieved radial current speed up to $0.75 \mathrm{~m} \mathrm{~s}^{-1}$. However, compared to Sentinel-1 for which the retrieval of these parameters is complicated by the spacecraft attitude control, in the case of SKIM, we can use the rotation of the antenna beams. The expected variations of the Doppler centroid $f_{\mathrm{DC}}=f_{\mathrm{NG}}+f_{\mathrm{G}}$ over one or several full rotations can be used to correct for attitude errors. Here we demonstrate that when using a matching algorithm, based on a $f_{\mathrm{NG}}$ model fitting, the amplitude of the velocity residue induced by the satellite attitude misknowledge can be decreased to $3 \mathrm{~cm} \mathrm{~s}^{-1}$.

The capability to estimate $\gamma_{0}$ and $\theta_{0}$ from the measured Doppler depends on the contents of the time series of $f_{\mathrm{GD}}$ and $f_{\mathrm{NG}}$. In cases when currents and Stokes drift are spatially uniform, the dominant geophysical signal $G U_{\mathrm{S}, \mathrm{R}}$ is dominated by the beam rotation frequency $\omega_{\mathrm{b}}$ (see Appendix A), whereas the beam mispointing only contains $2 \omega_{\mathrm{b}}$. However, any spatial structure in currents and Stokes drift will produce contributions at $2 \omega_{\mathrm{b}}$ that are mixed with the mispointing signal.

Fortunately, there are large differences between $f_{\mathrm{GD}}$ and $f_{\mathrm{NG}}$ for different incidence angles. At the SKIM angles $\cos \gamma \simeq 1$ and the mispointing errors at 12 and $6^{\circ}$ are almost the same (grey dashed lines and thick solid lines are superimposed in Fig. B2). In contrast, the geophysical signal is proportional to $\sin \gamma$ and doubles between 6 and $12^{\circ}$.

The following equation approximates the data model $D_{i}$ at the sample $i$ is the model used to fit the $\gamma_{0}$ and $\theta_{0}$ values in $f_{\mathrm{DC}}$,

$$
\begin{gathered}
D_{i}=f_{\mathrm{DC}, i}-\bar{f}_{\mathrm{NG}} \approx \sin \gamma_{i}\left(\cos \theta_{i} U_{\mathrm{p}}+\sin \theta_{i} V_{\mathrm{p}}\right) \\
+A_{k} \Delta f_{\mathrm{NG}, i, x} \\
+B_{k} \Delta f_{\mathrm{NG}, i, y}+N_{i} .
\end{gathered}
$$

In Eq. (B4), $f_{\mathrm{DC}, i}$ is the observed signal at the sample $i$, $\bar{f}_{\mathrm{NG}}$ is the value of $f_{\mathrm{NG}}$ for the nominal satellite attitude, $\left(U_{\mathrm{GD}, \mathrm{p}}, V_{\mathrm{GD}, \mathrm{p}}\right)$ is the geophysical velocity vector in the pixel $p$ at the sea surface (see below for pixel definition), $\left(\Delta f_{\mathrm{NG}, i, x}, \Delta f_{\mathrm{NG}, i, y}\right)$ is the decomposition of the satellite attitude misknowledge at the sample $i, N_{i}$ is the noise at the sample $i$ and $A_{k}=\gamma_{k} \cos \theta_{k}$ and $B_{k}=\gamma_{k} \sin \theta_{k}$ are the two parameters to be fitted to characterize the satellite attitude misknowledge expected to be stable during the period $k$. In the present study $k$ is equal to one full beam rotation.

Here the ground speed $\left(U_{\mathrm{p}}, V_{\mathrm{p}}\right)$ is taken constant in a given pixel $p$ at the sea surface. The pixel definition uses

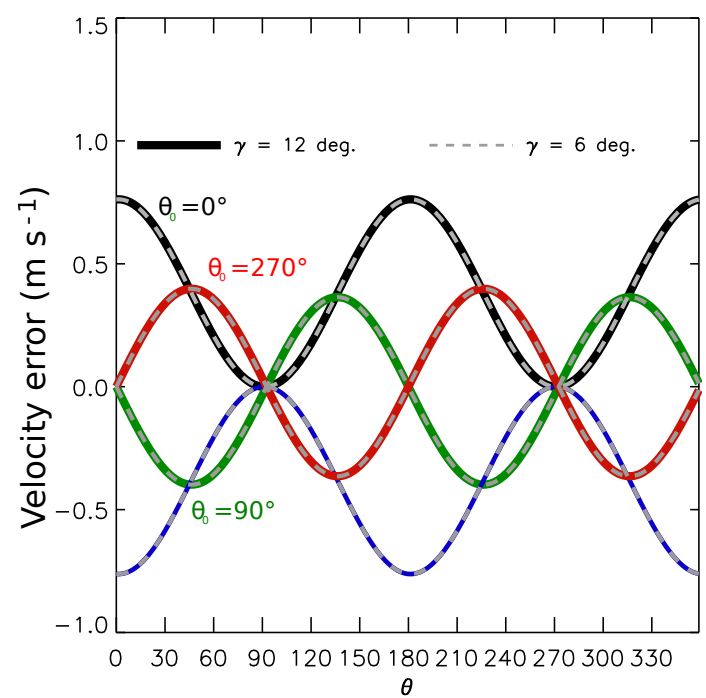

Figure B2. Velocity errors induced by satellite attitude misknowledge $\gamma_{0}=0.003^{\circ}$, as a function of the azimuth relative to the satellite track, and for four examples of $\theta_{0}$. The two beams incidence angles are superimposed (thick lines: $12^{\circ}$; thin dashed lines: $6^{\circ}$ ). These errors are dominated by a contribution at twice the beam rotation frequency $\omega_{\mathrm{b}}$.

the HEALPix spherical binning (Górski et al., 2005) with nside $=256$ equivalent to pixel area of $\approx 14 \times 14 \operatorname{arcmin}^{2}$, that is 25 by $25 \mathrm{~km}$. This binning provides pixels with the same surface on all the sphere and ease the software writing. Using Eq. (B4) the difference $R_{i, \mathrm{p}}$ is built from all $D_{i}$ inside a pixel to be independent from any $\left(U_{\mathrm{p}}, V_{\mathrm{p}}\right)$ values,

$$
\begin{aligned}
R_{i, \mathrm{p}} & =D_{i}-\mathbf{P} \cdot \mathbf{M}^{-1} \cdot\left(\begin{array}{c}
\sum_{j} \sin \gamma_{j} \cos \theta_{j} \mathbf{M}_{j} \\
\sum_{j} \sin \gamma_{j} \sin \theta_{j} \mathbf{M}_{j}
\end{array}\right) \\
& -A_{k} \Delta f_{\mathrm{NG}, i, x} \\
& +\mathbf{P} \cdot \mathbf{M}^{-1} \cdot\left(\begin{array}{c}
\sum_{j} \sin \gamma_{j} \cos \theta_{j} A_{k} \Delta f_{\mathrm{NG}, j, x} \\
\sum_{j} \sin \gamma_{j} \sin \theta_{j} A_{k} \Delta f_{\mathrm{NG}, j, x}
\end{array}\right) \\
& -B_{0, i} \Delta f_{\mathrm{NG}, i, y} \sin \gamma_{j} \cos \theta_{j} B_{k} \Delta f_{\mathrm{NG}, j, y} \\
& +\mathbf{P} \cdot \mathbf{M}^{-1} \cdot\left(\begin{array}{l}
\sum_{j}^{j} \sin \gamma_{j} \sin \theta_{j} B_{k} \Delta f_{\mathrm{NG}, j, y}
\end{array}\right),
\end{aligned}
$$

with

$$
\begin{aligned}
\mathbf{P} & =\left(\begin{array}{l}
\sin \gamma \cos \theta_{j} \\
\sin \gamma \sin \theta_{j}
\end{array}\right) \\
\mathbf{M} & =\left(\begin{array}{cc}
\sum_{j} \sin ^{2} \gamma_{j} \cos ^{2} \theta_{j} & \sum_{j} \sin ^{2} \gamma_{j} \cos \theta_{j} \sin \theta_{j} \\
\sum_{j} \sin ^{2} \gamma_{j} \cos \theta_{j} \sin \theta_{j} & \sum_{j} \sin ^{2} \gamma_{j} \sin ^{2} \theta_{j}
\end{array}\right) .
\end{aligned}
$$


It is important to understand that several rotations are solved together; otherwise the matrix $\mathbf{M}$ cannot be inverted by lack of redundant information in the same pixel. Thus, set of $\gamma_{k}$ and $\theta_{k}$ values are extracted by minimizing the $\chi^{2}=\sum_{\mathrm{p}, i}\left(R_{i, \mathrm{p}}^{2}\right)$ combining different $\gamma$ beams over several antenna rotations to increase the azimuth sampling. There is still potential correlation between $\Delta f_{\mathrm{NG}}\left(\gamma_{0}, \theta_{0}\right)$ and geophysical Doppler frequency shifts because the hypothesis that $\left(U_{\mathrm{p}}, V_{\mathrm{p}}\right)$ does not vary in time is not exactly true. The time variation between different measurements using different beams produces residual signal correlated with the time variation of the geophysical signal. Thus, the $\Delta f_{N G}\left(\gamma_{0}, \Theta_{0}\right)$ fit is partly correlated with the geophysical information.

Instrument noise does not introduce an average bias as long as it is not correlated in time and not correlated to the linear fit of $\Delta f_{\mathrm{NG}}\left(\gamma_{0}, \theta_{0}\right)$. Further investigation will check the level of the expected correlation between $\Delta f_{\mathrm{NG}}\left(\gamma_{0}, \theta_{0}\right)$ and the noise. In our estimates, the reconstructed values of the pair $\left(\gamma_{0}, \theta_{0}\right)$ are only affected by the correlation between the non-geophysical and geophysical signals.

Simulations have been done to include random drifts of the satellite attitude within $10^{-4} \circ \mathrm{s}^{-1}$ variations. Geophysical Doppler contributions $f_{\mathrm{GD}}$ have been computed from surface currents and wave-induced biases estimated from numerical models of the ocean circulation and waves. The case of the Oregon coast is illustrated in Fig. B3. The standard deviation of the error on Doppler velocity is found to be around $0.04 \mathrm{~m} \mathrm{~s}^{-1}$ after cleaning and is related to the correlation between the two simulated values of $\Delta f_{\mathrm{NG}}\left(\gamma_{0}, \theta_{0}\right)$ and $f_{\mathrm{GD}}$. The error induced by the satellite attitude misknowledge is typically higher when the signal has more structures. This advocates for averaging the determination of these errors over a larger data set. This is possible if the satellite attitude is more stable or the drift follows physical law decoupled from expected $f_{\mathrm{GD}}$ signal.

In conclusion, the case of the Oregon coast illustrated in Fig. B3 shows that the cleaned velocity error is relatively small $\left(<0.04 \mathrm{~m} \mathrm{~s}^{-1}\right)$. The algorithm has been tested on other regions (not illustrated here) with similar but often better results.
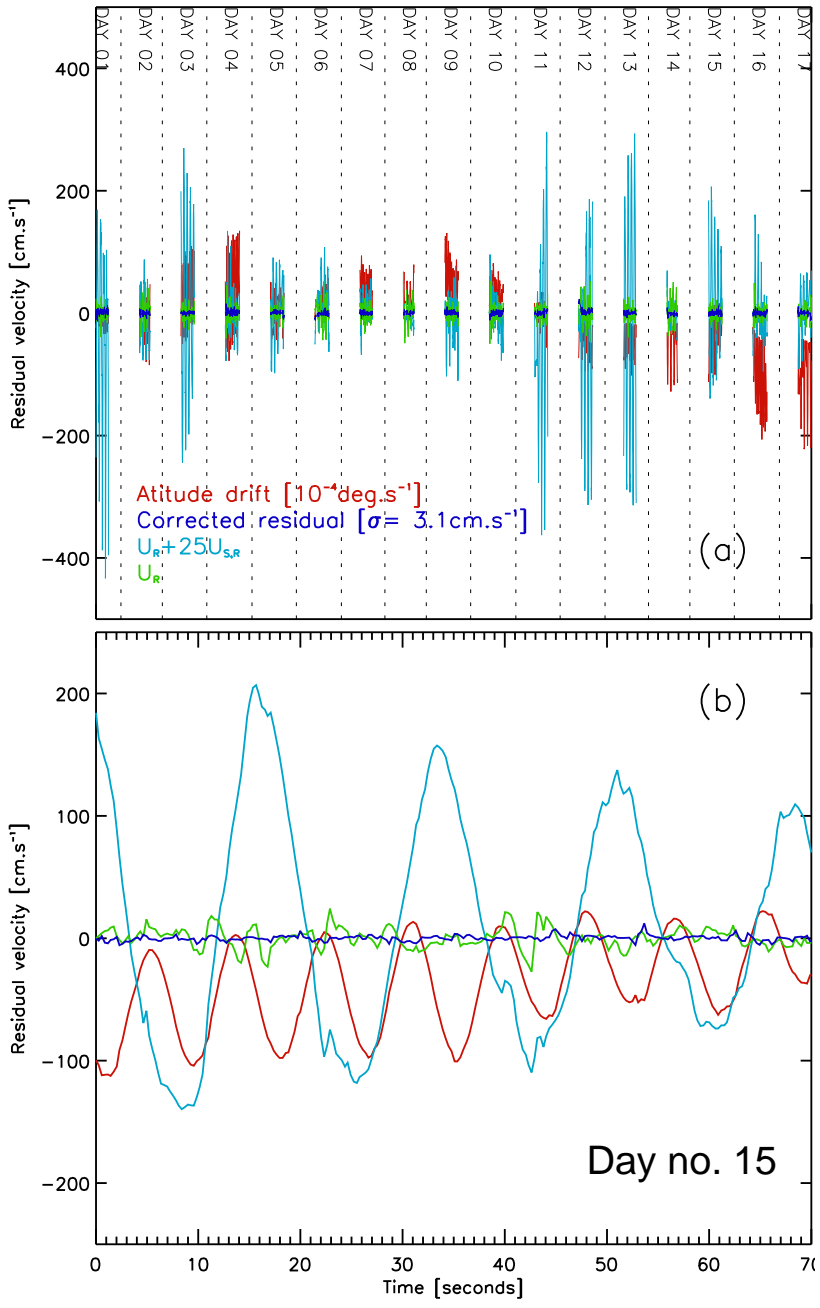

Figure B3. Velocity residual error (in $\mathrm{cm} \mathrm{s}^{-1}$ ) for the Oregon coast simulations non-corrected (red curve) and corrected (blue curve) by removing the fit of the satellite attitude misknowledge, combining beams and eight $\left(\gamma_{0}, \theta_{0}\right)$ pairs by antenna rotation. (a) Simulated data over one satellite pass for day 21. (b) Results for all satellite passes in the domain shown in Fig. 6. This time frame in September 2014 includes winds speeds up to $22 \mathrm{~m} \mathrm{~s}^{-1}$. For each pass the duration is stretched over $20 \mathrm{~h}$ in order to make it visible. $U_{\mathrm{R}}$ and $U_{\mathrm{R}, \mathrm{S}}$ signals are also shown for scale. The satellite attitude drifts

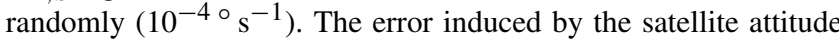
misknowledge is higher when the geophysical signal is stronger and less uniform. 
Author contributions. All authors have contributed to the writing of the paper. The wave bias error analysis was performed by FA, GM and EC analyzed the Doppler centroid estimation error, JMD, CT and EC analyzed the error due to platform attitude. LG and $\mathrm{CU}$ combined these errors to produce simulated data that was used by JX for DFS analysis with TOPAZ. The optimal interpolation scheme was adapted by $\mathrm{CU}$ and will be described elsewhere in more detail.

Competing interests. The authors declare that they have no conflict of interest.

Acknowledgements. Support from LabexMer via grant ANR-10LABX-19-01, and Copernicus Marine Environment Monitoring Service (CMEMS) as part of the Service Evolution program is gratefully acknowledged. Additional support from CNES was given through the VASCO phase 0 study and R \& T contracts.

Edited by: Eric J. M. Delhez

Reviewed by: Mark Bourassa and two anonymous referees

\section{References}

Aksenov, Y., Popova, E. E., Yool, A., Nurser, A. G., Williams, T. D., Bertino, L., and Bergh, J.: On the future navigability of Arctic sea routes: High-resolution projections of the Arctic Ocean and sea ice, Marine Policy, 75, 300-317, https://doi.org/10.1016/j.marpol.2015.12.027, 2017.

Ardhuin, F., Marié, L., Rascle, N., Forget, P., and Roland, A.: Observation and estimation of Lagrangian, Stokes and Eulerian currents induced by wind and waves at the sea surface, J. Phys. Oceanogr., 39, 2820-2838, https://doi.org/10.1175/2009JPO4169.1, 2009.

Ardhuin, F., Chapron, B., Collard, F., Smith, M., Stopa, J., Thomson, J., Doble, M., Wadhams, P., Blomquist, B., Persson, O., and Collins III, C. O.: Measuring ocean waves in sea ice using SAR imagery: A quasi-deterministic approach evaluated with Sentinel-1 and in situ data, Remote Sens. Environ., 189, 211222, https://doi.org/10.1016/j.rse.2016.11.024, 2017a.

Ardhuin, F., Rascle, N., Chapron, B., Gula, J., Molemaker, J., Gille, S. T., Menemenlis, D., and Rocha, C.: Small scale currents have large effects on wind wave heights, J. Geophys. Res., 122, 45004517, https://doi.org/10.1002/2016JC012413, 2017b.

Barrick, D. E.: First order theory and analysis of MF/HF/VHF scatter from the sea, IEEE T. Antennas Propagat., AP-20, 2-10, 1972.

Bonjean, F. and Lagerloef, G. S. E.: Diagnostic Model and Analysis of the Surface Currents in the Tropical Pacific Ocean, J. Phys. Oceanogr., 32, 2938-2954, https://doi.org/10.1175/15200485(2002)032<2938:DMAAOT>2.0.CO;2, 2002.

Bourassa, M. A., Rodriguez, E., and Chelton, D.: Winds and current mission: Ability to observe mesoscale air/sea coupling, in: Proceedings of IEEE International Geoscience and Remote Sensing Symposium (IGARSS), Beijing, China, 7392-7395, https://doi.org/10.1109/IGARSS.2016.7730928, 2016.
Buck, C.: An extension to the wide swath ocean altimeter concept, in: vol. 8, Proceedings of the IEEE International Geoscience and Remote Sensing Symposium (IGARSS), Seoul, Korea, 5435439, https://doi.org/10.1109/IGARSS.2005.1525970, 2005.

Cardinali, C., Pezzulli, S., and Andersson, E.: Influence-matrix diagnostic of a data assimilation system, Q. J. Roy. Meteorol. Soc., 130, 2767-2786, 2004.

Caudal, G., Hauser, D., Valentin, R., and Gac, C. L.: KuROS: A New Airborne Ku-Band Doppler Radar for Observation of Surfaces, J. Atmos. Ocean Tech., 31, 2023-2245, https://doi.org/10.1175/JTECH-D-14-00013.1, 2014.

Chapron, B., Collard, F., and Ardhuin, F.: Direct measurements of ocean surface velocity from space: interpretation and validation, J. Geophys. Res., 110, C07008, https://doi.org/10.1029/2004JC002809, 2005.

Collard, F., Mouche, A., Chapron, B., Danilo, C., and Johannessen, J.: Routine High Resolution Observation Of Selected Major Surface Currents From Space, in: Proceedings of SEASAR 2008, SP-656, ESA, ESA - ESRIN, Frascati, Italy, http://earth.esa.int/workshops/seasar2008/participants/287/ pres_287_Collard.pdf (last access: 12 April 2018), 2008.

Cravatte, S., Kessler, W. S., Smith, N., Wijffels, S. E., and Contributing Authors: First Report of TPOS 2020, GOOS-215, 200 pp., http://tpos2020.org/first-report/ (last access: 12 April 2018), 2016.

Elfouhaily, T., Chapron, B., Katsaros, K., and Vandemark, D.: A unified directional spectrum for long and short wind-driven waves, J. Geophys. Res., 102, 15781-15796, 1997.

Elipot, S., Lumpkin, R., Perez, R. C., Lilly, J. M., Early, J. J., and Sykulski, A. M.: A global surface drifter data set at hourly resolution, J. Geophys. Res., 121, 2937-2966, https://doi.org/10.1002/2016JC011716, 2016.

Forget, P., Saillard, M., and Broche, P.: Observations of the sea surface by coherent L band radar at low grazing angles in a nearshore environment, J. Geophys. Res., 111, C09015, https://doi.org/10.1029/2005JC002900, 2006.

Forget, P., Saillard, M., Guérin, C.-A., Testud, J., and Bouar, E. L.: On the Use of X-Band Weather Radar for Wind Field Retrieval in Coastal Zone, J. Atmos. Ocean Tech., 82, 899-917, https://doi.org/10.1175/JTECH-D-15-0206.1, 2016.

Fu, L.-L. and Ubelmann, C.: On the Transition from Profile Altimeter to Swath Altimeter for Observing Global Ocean Surface Topography, J. Atmos. Ocean Tech., 31, 560-568, 2014.

Gille, S. T. and Hughes, C. W.: Aliasing of high-frequency variability by altimetry: Evaluation from bottom pressure recorders, Geophys. Res. Lett., 28, 1755-1758, https://doi.org/10.1029/1999GL011263, 2001.

Goldstein, R. M. and Zebker, H. A.: Interferometric radar measurement of ocean surface current, Nature, 328, 707-709, 1987.

Górski, K. M., Hivon, E., Banday, A. J., Wandelt, B. D., Hansen, F. K., Reinecke, M., and Bartelmann, M.: HEALPix: A Framework for High-Resolution Discretization and Fast Analysis of Data Distributed on the Sphere, Astrophys. J., 622, 759-771, https://doi.org/10.1086/427976, 2005.

Gula, J., Molemaker, M. J., and Mcwilliams, J. C.: Gulf Stream Dynamics along the Southeastern U.S. Seaboard, J. Phys. Oceanogr., 45, 690-715, 2015. 
Hauser, D., Tison, C., Amiot, T., Delaye, L., Corcoral, N., and Castillan, P.: SWIM: The First Spaceborne Wave Scatterometer, IEEE T. Geosci. Remote, 55, 3000-3014, 2017.

Horvat, C., Tziperman, E., and Campin, J.-M.: Interaction of sea ice floe size, ocean eddies and sea ice melting, Geophys. Res. Lett., 43, 8083-8090, https://doi.org/10.1002/2016GL069742, 2016.

Isern-Fontanet, J., Ballabrera-Poy, J., Turiel, A., and GarcíaLadona, E.: Remote sensing of ocean surface currents: a review of what is being observed and what is being assimilated, Nonlin. Processes Geophys., 24, 613-643, https://doi.org/10.5194/npg24-613-2017, 2017.

Jackson, F. C., Walton, W. T., and Peng, C. Y.: A comparison of in situ and airborne radar observations of ocean wave directionality, J. Geophys. Res., 90, 1005-1018, 1985.

Jenkins, A. D.: The use of a wave prediction model for driving a near-surface current model, Deut. Hydrogr. Z., 42, 133-149, 1989.

Johannessen, O. M., Johannessen, J. A., Morison, J., Farrelly, B. A., and Svendsen, E. A. S.: OceanographicC onditionsi $n$ the Marginal Ice Zone North of Svalbard in Early Fall 1979 With an Emphasis on Mesoscale Processes, J. Geophys. Res., 88, 27552769, 1983.

Kenyon, K. E.: Stokes drift for random gravity waves, J. Geophys. Res., 74, 6991-6994, 1969.

Kim, S. Y. and Kosro, P. M.: Observations of nearinertial surface currents off Oregon: Decorrelation time and length scales, J. Geophys. Res., 118, 3723-3736, https://doi.org/10.1002/jgrc.20235, 2013.

Kim, S. Y., Terrill, E. J., and Cornuelle, B. D.: Mapping surface currents from HF radar radial velocity measurements using optimal interpolation, J. Geophys. Res., 113, C10023, https://doi.org/10.1029/2007JC004244, 2008.

Kirby, J. T. and Chen, T.-M.: Surface waves on vertically sheared flows: approximate dispersion relations, J. Geophys. Res., 94, 1013-1027, 1989.

Korosov, A. A. and Rampal, P.: A Combination of Feature Tracking and Pattern Matching with Optimal Parametrization for Sea Ice Drift Retrieval from SAR Data, Remote Sensing, 9, 258, https://doi.org/10.3390/rs9030258, 2017.

Kuik, A. J., van Vledder, G. P., and Holthuijsen, L. H.: A method for the routine analysis of pitch-and-roll buoy wave data, J. Phys. Oceanogr., 18, 1020-1034, https://doi.org/10.1175/15200485(1988)018<1020:amftra>2.0.co;2, 1988.

Lipa, B. J. and Barrick, D. E.: Least-squares methods for the extraction of surface currents from CODAR crossed-loop data: Application at ARSLOE, IEEE J. Ocean. Eng., 8, 226-253, 1983.

Martin, A. C. H., Gommenginger, C., Marquez, J., Doody, S., Navarro, V., and Buck, C.: Wind-wave-induced velocity in ATI SAR ocean surface currents: First experimental evidence from an airborne campaign, J. Geophys. Res., 121, 1640-1653, https://doi.org/10.1002/2015JC011459, 2016.

Mouche, A. A., Chapron, B., and Reul, N.: Predicted Doppler shifts induced by ocean surface wave displacements using asymptotic electromagnetic wave scattering theories, Waves Random Complex Media, 18, 185-196, https://doi.org/10.1080/17455030701564644, 2008.

Nouguier, F., Chapron, B., Collard, F., Mouche, A., Rascle, N., Ardhuin, F., and Wu, X.: Sea surface kinematics from near- nadir radar measurements, IEEE T. Geosci. Remote, http://tiny. cc/SKIMonRG_NOUG, in press, 2018.

Peureux, C., Benetazzo, A., and Ardhuin, F.: Note on the directional properties of meter-scale gravity waves, Ocean Sci., 14, 41-52, https://doi.org/10.5194/os-14-41-2018, 2018.

Ponte, A. L., Klein, P., Dunphy, M., and Le Gentil, S.: Low-mode internal tides and balanced dynamics disentanglement in altimetric observations: Synergy with surface density observations, J. Geophys. Res., 122, 2143-2155, https://doi.org/10.1002/2016JC012214, 2017.

Poulain, P.-M., Bussani, A., Gerin, R., Jungwirth, R., Mauri, E., Menna, M., and Notarstefano, G.: Mediterranean surface currents measured with drifters: From basin to subinertial scales, Oceanography, 26, 38-47, https://doi.org/10.5670/oceanog.2013.03, 2016.

Raney, R. K.: Doppler properties of radars in circular orbits, Int. J. Remote Sens., 7, 1153-1162, 1986.

Rascle, N. and Ardhuin, F.: A global wave parameter database for geophysical applications. Part 2: model validation with improved source term parameterization, Ocean Model., 70, 174188, https://doi.org/10.1016/j.ocemod.2012.12.001, 2013.

Rio, M.-H., Mulet, S., and Picot, N.: Beyond GOCE for the ocean circulation estimate: Synergetic use of altimetry, gravimetry, and in situ data provides new insight into geostrophic and Ekman currents, Geophys. Res. Lett., 41, 8918-8925, https://doi.org/10.1002/2014GL061773, 2014.

Rocha, C. B., Chereskin, T. K., and Gille, S. T.: Mesoscale to Submesoscale Wavenumber Spectra in Drake Passage, J. Phys. Oceanogr., 46, 601-620, https://doi.org/10.1175/JPO-D15-0087.1, 2016.

Roland, A. and Ardhuin, F.: On the developments of spectral wave models: numerics and parameterizations for the coastal ocean, Ocean Dynam., 64, 833-846, https://doi.org/10.1007/s10236014-0711-z, 2014.

Romeiser, R., Runge, H., Suchandt, S., Kahle, R., Rossi, C., and Bell, P.: Quality Assessment of Surface Current Fields From TerraSAR-X and TanDEM-X Along-Track Interferometry and Doppler Centroid Analysis, IEEE T. Geosci. Remote, 52, 2759 2772, https://doi.org/10.1109/TGRS.2013.2265659, 2014.

Rouault, M. J., Mouche, A., Collard, F., Johannessen, J. A., and Chapron, B.: Mapping the Agulhas Current from space: An assessment of ASAR surface current velocities, J. Geophys. Res., 41, C10026, https://doi.org/10.1029/2009JC006050, 2010.

Sakov, P., Counillon, F., Bertino, L., Lisæter, K. A., Oke, P. R., and Korablev, A.: TOPAZ4: an ocean-sea ice data assimilation system for the North Atlantic and Arctic, Ocean Sci., 8, 633-656, https://doi.org/10.5194/os-8-633-2012, 2012.

Shrira, V. I., Ivonin, D. V., Broche, P., and de Maistre, J. C.: On remote sensing of vertical shear of ocean surface currents by means of a single-frequency VHF radar, Geophys. Res. Lett., 28, 39553958, 2001.

SKIM Team: Sea surface KInematics Multiscale monitoring, full proposal for ESA EE9, Tech. rep., Laboratoire d'Océanographie Physique et Spatiale, Brest, France, prepared for European Space Agency, $192 \mathrm{pp}$., https://doi.org/10.13140/RG.2.2.18902.86084/1, 2017.

Stammer, D., Wunsch, C., and Ponte, R. M.: De-aliasing of global high frequency barotropic motions in altime- 
ter observations, Geophys. Res. Lett., 27, 1175-1176, https://doi.org/10.1029/1999GL011263, 2000.

Stokes, G. G.: On the theory of oscillatory waves, Trans. Camb. Philos. Soc., 8, 441-455, 1849.

Sudre, J., Maes, C., and Garçon, V.: On the global estimates of geostrophic and Ekman surface currents, Limnol. Oceanogr., 3, 1-20, https://doi.org/10.1215/21573689-2071927, 2013.

Sutherland, P. and Gascard, J. C.: Airborne remote sensing of ocean wave directional wavenumber spectra in the marginal ice zone, Geophys. Res. Lett., 43, 4659-4664, https://doi.org/10.1002/grl.53444, 2016.

Thomson, J., D’Asaro, E. A., Cronin, M. F., Rogers, W. E., Harcourt, R. R., and Shcherbina, A.: Waves and the equilibrium range at Ocean Weather Station P, J. Geophys. Res., 118, 5955962, https://doi.org/10.1002/2013JC008837, 2013.

Ubelmann, C., Cornuelle, B., and Fu, L.-L.: Dynamic Mapping of Along-Track Ocean Altimetry: Method and Performance from Observing System Simulation Experiments, J. Atmos. Ocean Tech., 33, 1691-1699, https://doi.org/10.1175/JTECH-D15-0163.1, 2016. van Sebille, E., Wilcox, C., Lebreton, L., Maximenko, N., Hardesty, B. D., van Franeker, J. A., Eriksen, M., Siegel, D., Galgani, F., and Law, K. L.: A global inventory of small floating plastic debris, Environ. Res. Lett., 10, 124006, https://doi.org/10.1088/1748-9326/10/12/124006, 2015.

Wollstadt, S., López-Dekker, P., De Zan, F., and Younis, M.: Design Principles and Considerations for Spaceborne ATI SAR-Based Observations of Ocean Surface Velocity Vectors, IEEE T. Geosci. Remote, 99, 1-20, https://doi.org/10.1109/TGRS.2017.2692880, 2016.

Xie, J., Bertino, L., Counillon, F., Lisæter, K. A., and Sakov, P.: Quality assessment of the TOPAZ4 reanalysis in the Arctic over the period 1991-2013, Ocean Sci., 13, 123-144, https://doi.org/10.5194/os-13-123-2017, 2017.

Yurovsky, Y. Y., Kudryavtsev, V. N., Chapron, B., and Grodsky, S. A.: Sea surface kinematics from nearnadir radar measurements, IEEE T. Geosci. Remote, https://doi.org/10.1109/TGRS.2017.2787459, in press, 2018.

Zrnic, D. S.: Spectral Moment Estimates from Correlated Pulse Pairs, IEEE T. Aero. Elect. Syst., 13, 344-354, https://doi.org/10.1109/TAES.1977.308467, 1977. 